\title{
The Impact of Managerial Ability on the Relation between Real Earnings Management and Future Firm's Performance: Applied Study
}

\author{
Mohamed Ibrahim Mohamed Hessian \\ Accounting and Auditing Dep. \\ Faculty of Commerce \\ Ain Shams University \\ Cairo, Egypt \\ Email: dr.mohamedhussien@.commerce.asu.edu.eg
}

Received October, 2018; December, 2018

\begin{abstract}
This study aims to investigate the managerial ability of executives' managers' role in mitigating the negative impact of real earnings management on future firm's performance. The researcher operationalizes managerial ability by using a measure developed by Demerjian, Lev, and McVay (2012). This measure captures managers' ability to efficiently convert firm resources into sales revenue relative to their industry peers. In other words, higher-ability managers are more likely to generate more sales revenue for a given set of resources compared to lower-ability managers. The researcher follows Roychowdhury (2006) and Kothari et al. (2016) to calculate abnormal sales, abnormal production costs, and abnormal discretionary expenses. To capture the total effects of three REM methods an aggregate REM that is a proxy for real earnings activities was used. Following Gunny (2010) and Huang \& Sun (2017) future performance proxies are ROA and operating cash flows to total assets (CFO) for the next three years each year. Using a panel sample of 605 firm-year observations from 2005 to 2015 . The study concluded that there is a positive significant relationship between the managerial ability of managers and earnings management through manipulating real operational activities.
\end{abstract}

Keywords: Managerial Ability; Real Earnings Management; Future Firm Performance.

Type: Research paper

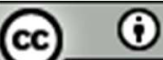

This work is licensed under a Creative Commons Attribution 4.0 International License.

\section{DOI: 10.51325/ijbeg.v2i1.53}

تأثير القدرة الإدارية للمديرين على العلاقة ما بين إدارة الأرباح الحقيقية والأداء المستقبلي لمنشآت الأعمال:

استهدف البحث الحالي دراسة دور القدرة الإدارية للمديرين التنفيذين في تخفيض الأثر السلبي لأنشطة إدارة الارباح

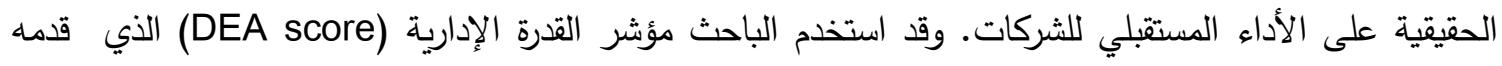
لقياس القدرة الإدارية للمديرين بناء على كفاء استغلال المديرين Demerjian, Lev, and McVay (2012) للموارد المتاحة وتحقق أعلى مقدار من المخرجات مقارنةً بالمديرين الآخرين في نفس الصناعة، أما إدارة الأنثطة

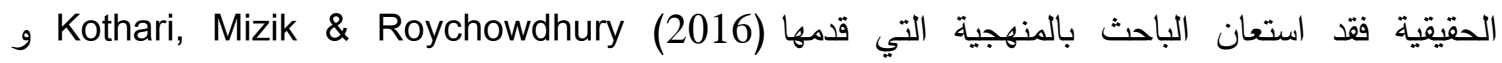
Rowchowdhury (2006) على الأداء المستقبلي من خلال معدل العائد على الأصول (ROA) والتدفقات النقدية

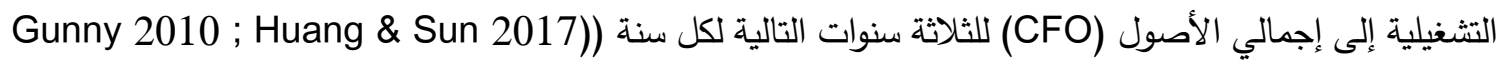


• وقد تمت الدراسة من خلال تحليل قطاعي زمني Panel Data يغطي السنوات من 2005 إلى 2015 لـ 55 . شركة. وقد خلصت نتائج الدراسة إلى وجود علاقة إيجابية وجوهرية بين القدرة الإدارية للمديرين وممارسة إدارة الأرباح من خلال التلاعب بالأنثطة التثغيلية الحقيقية. وهي النتيجة التي تقترح استثمار المديرين لقدراتهم ومهاراتهم في التلاعب بالأرباح من خلال ممارسة أنشطة إدارة الأرباح الحقيقة بزيادة حجم المبيعات بثكل وهمي، تحقيق مستويات غير عادية من الإنتاج، والتحكم في النفقات الاختيارية بهدف توجيه الأرباح لمستويات معينة مستهدفة سلفاً، وذلك الكالك كبديل عن استخدام الإدارة لمهاراتهم وقدراتهم الإدارية في تحقيق المستهدف من الأرباح دون الانخراط في تلك الكات

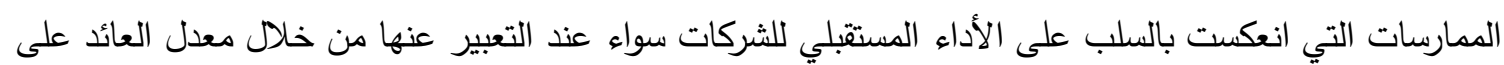
الأصول (ROA) والتدفقات النقدية التشغيلية إلى إجمالي الأصول (CFO) للثلاثة سنوات التالية دون وجود تأثير للقدرة الإدارية للديرين على تخفيض ذلك الأثر السلبي للأنثطة الحقيقية لإدارة الأرباح على الأداء المستقبلي ل اللشركات. مصطلحات الدراسة: القدرة الإدارية للمديرين، إدارة الأرباح الحقيقية، الأداء المستقبلي لمنشآت الأعمال.

مقدمة: تعد القدرة الإدارة للمديرين التنفيذين وبلا شك أحد العناصر الأساسية لنجاح الثركات في بيئة الأعمـال (Andreou,Philip, \& Robejsek, من خلال الدور الاقتصادي الذي يقوم به المديرون في خيارات شركاتهم وأدائها 2016; Bamber, Jiang, \& Wang, 2010; Chemmanur, Paeglis, \& Simonyan, 2010; Choi, Han, Jung, \& Kang, 2015; Demerjian, Lev, \& McVay, 2013; Francis, Ren, Sun, \& Qiang, (2016. ولذلك، فإن القدرات الإدارية (خصائص المديرين) بما في ذلك القدرة والموهبة والسمعة ونمط الإدارة مهمة للبحوث والتطبيقات العملية في مجالات الاقتصاد والمالية والمحاسبة والإدارة. حيث يتمتع المديرون الأكثر قدرة بمعارف مهنية أقوى تتعلق بالثركة، مما يمكنهم من اتخاذ أحكام وقرارات أفضل. فالمديرون الأكثر يتمتعون بفهم

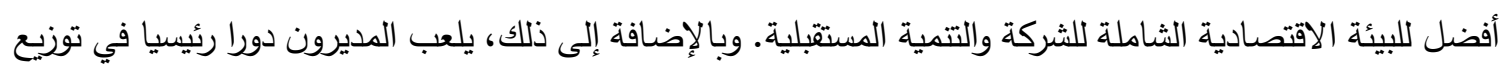
موارد الشركة، وكذلك والقدرة على تطبيق المعايير المحاسبية بمزيد من المرونة، وبالتالي يكون لهم تأثير كبير على بلى دئه

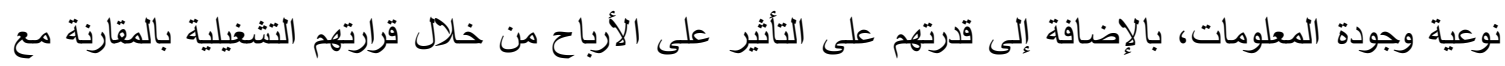
المديرين الأقل قدرة.

وبالإضافة إلى ذلك، يظهر المديرون الأكثر قدرة على فهم أكثر مرونة وتطبيق المعايير المحاسبية. ولذلك، فإن التقارير المالية الموجه من المديرين للمستثرين تختلف وفقا لنوايا المديرين وخيارات المديرين. ويمكن للمديرين الأكثر قدرة على تخصيص الموارد بشكل أفضل، وإحداث تأثير إيجابي على نوعية التقارير المالية. كما توفر البحوث

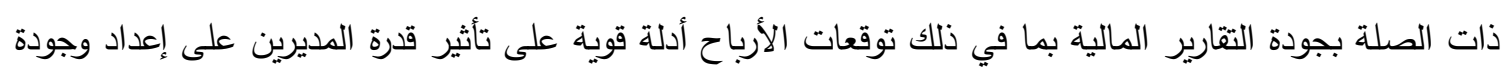

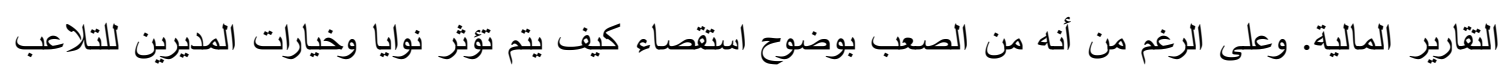
في نوعية التقارير المالية، بالمقارنة مع المديرين الأقل قدرة.

وتؤثر قدرة المديرين حتما على دقة وملاءمة التقارير المالية، ولذلك، فإنه بالتالي يؤثرون أيضا على تتمية بالية

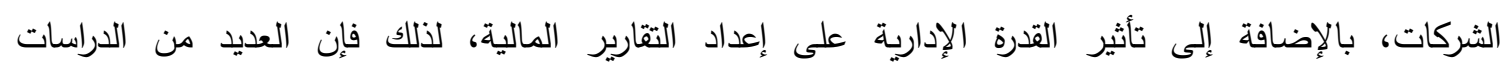

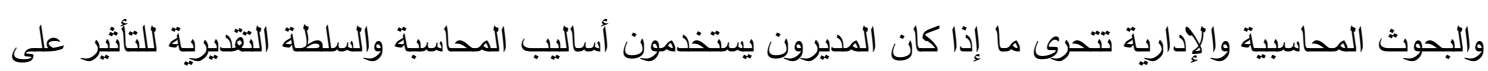
الأرباح المعن عنها، أو ما يسمى بإدارة الأرباح وفي الوقت نفسه، وينظم إعداد التقارير المالية المعايير المحاسبية، 
ويختار المديرون التخخل في التقارير المالية من خلال إدارة الأرباح، وقد يأتي ذلك من التدخل الانتهازي في الأرباح

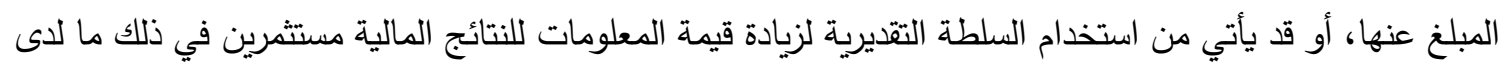
المديرين من فهم أفضل للصناعة والبيئة جنبا إلى جنب مع السلطة التقديرية المتاحة من خلال المبات المعايير المحاسبية،

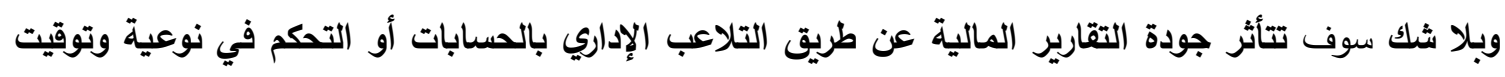
القرارات، سواء التثغيلية أو الاستثمارية أو التمويلية.

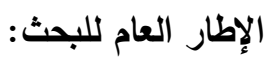

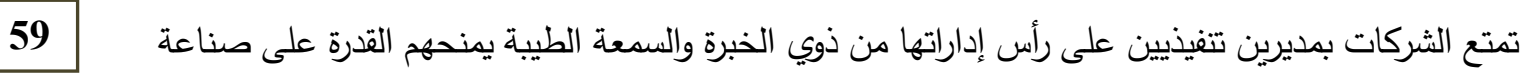

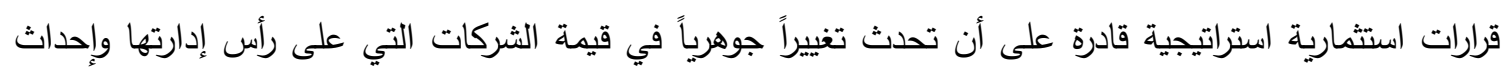
طفرة في ثروات ومصالح المساهمين، ليس هذا فحسب، بل الأمر يمتد إلى الأطراف الخارجية المتعاملة مع تلك فئك

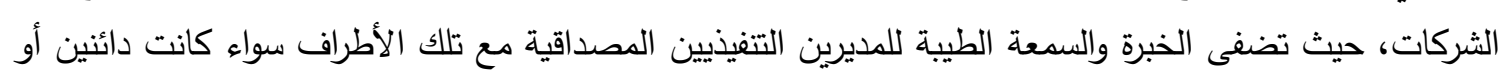

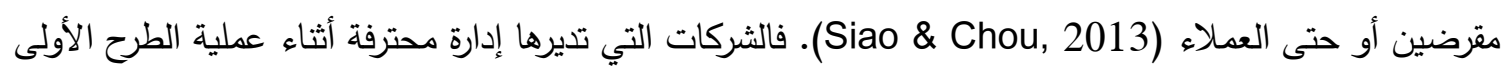

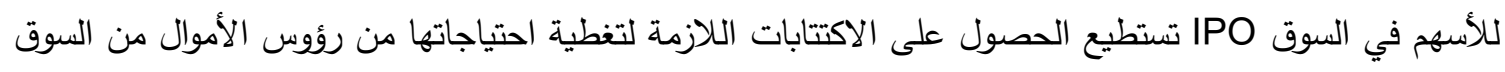
دون الحاجة إلى تقديم مزايا أو أدوات ترويجيه تلجأ لها الثركات لضمان الضمان حثد رؤوس الأموال من السوق لتغطية احتياجاتها وجذب المستثمرين من المؤسسات بحيازات كبيرة، والتي ممكن أن تحمل في طياها تأثيرا إيجابيا على كفاءة التهات

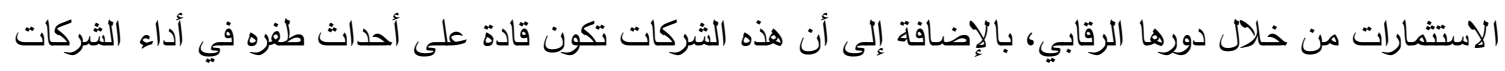

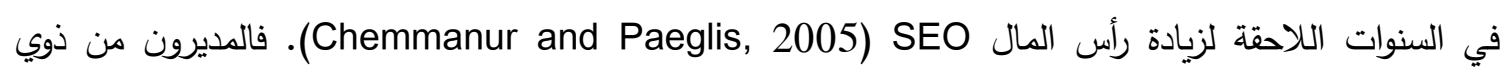
المهارات الإدارية يتمتعون بمهارات اقتتاص الفرص الاستثمارية التي تحقق طفرة في قيمة الشركات التي يتولون إداراتها باختيارهم مشروعات ذات صافي القيمة حالية الموجبة والمرتفعة مع امتلاكهم المقدرة على تتفيذ تلك المشاريع

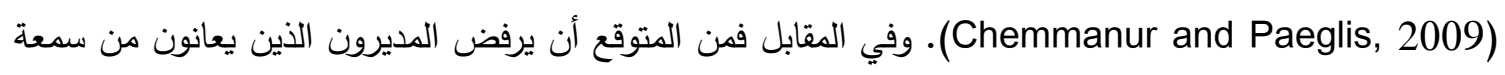

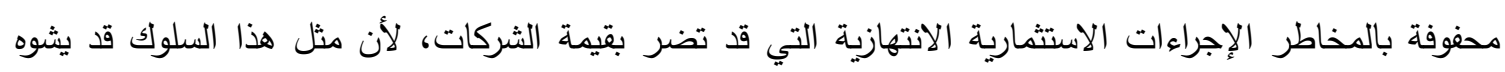

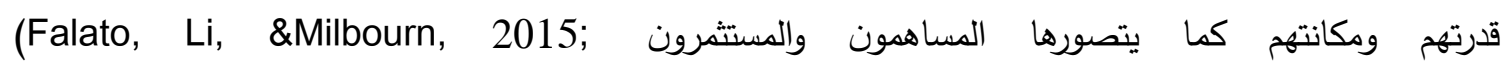
. Graham,Harvey,\&Puri, 2013) واجمالاً، فإن المشاركون في السوق قد يتأثرون بوجود مديرين عالي الجودة في الشركة لأنهج يثقون في قدرة

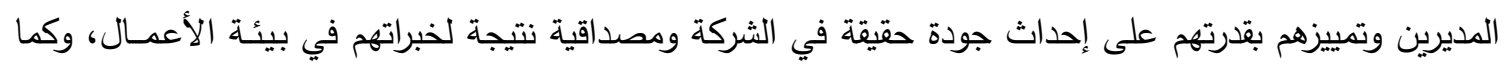

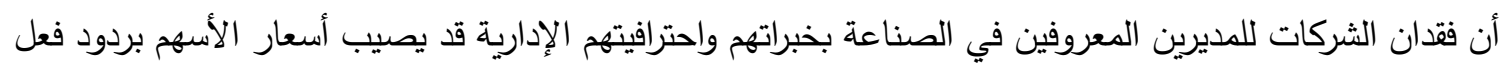

سلبية لا يمكن أغفالها (Hayes and Schaefer, 1999). وتتماشى التحليلات السابقة لتأثير القدرة الإدارية للمديرين على قرارات الشركات على نظرية الصفوف العليا managerial والتي تقوم على فرضيتها على وجود تأثير للخصائص الإدارية Upper echelons theory

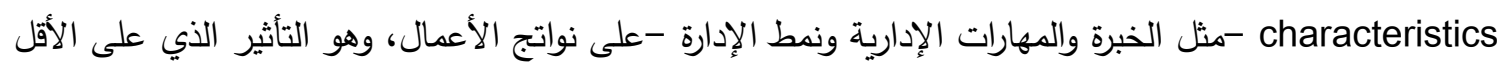

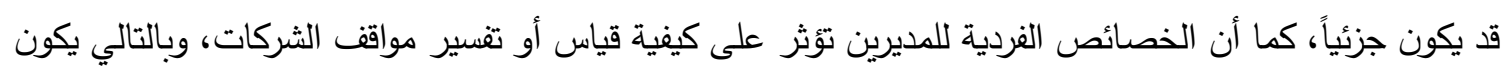
لها تأثير على قرارات الشركات وأدائها (Ge, Matsumoto, \& Zhang, 2011; Hambrick, 2007). وقد أند خضعت النظرية للدراسة من عدة جوانب، منها العلاقة بين تأثير الخبرة المالية للمديرين الماليين على التعديلات في القوائم المالية نتيجة الأخطاء المحاسبية (Aier, Comprix, Gunlock,\&Lee, 2005)، فالخبرة المالية للمديرين تقلل من تكرارية التعديل في القوائم المالية الناتجة عن حدوث أخطاء في فترات سابقة، وتأثير سمعة المدير التنفيذي 
على جودة الأرباح المحاسبية (Francis, Huang, Rajgopal,\& Zang, 2008)، فكبار المديرين التتفيذيين ذوي السمعة الطيبة مرتبطون بشركات ذات جودة أرباح أقل، ليس لأن هؤلاء المديرين التنفيذيين يتخذون إجراءات تقديرية لتقليل جودة الأرباح؛ ولكن لأن المديرين التنفيذيين ذوي السمعة الطيبة يعملون في ظل بيئة تثغيلية أكثر تعقيداً وتقلب، وهي العوامل التي تؤدي إلى ضعف جودة الإيرادات، وهي نفس العوامل التي تتطلب مهارات متفوقة من كبار المديرين التتفيذيين، وليس فقط السمعة الطيبة فحسب، وتأثير النمط الإداري للمديرين علي أنشطة التجنب الضرئي (Dyreng,Hanlon,\& Maydew, 2010; Francis, Sun, \& Wu, 2015 and Koester, للشركات (2016 Shevlin, Wangerin بالمديرين الأقل في القدرات الإدارية ـ وتقدم هذه الدراسات مجتمعة أدلة تدعم أهمية الخصائص الإدارية للمديرين التتفيذيين في قرارات الثركات وأدائها. وفي مقابل كل ما سبق، فإن هناك اتجاه مغاير للدارسات التي سبق الإثارة اليها يقدم أدلة إلى أن المديرين ذوي القدرات الإدارية قد يتورطون في ممارسات غير مستنيرة للاستثمارات أو إدارة الارباح لتحقيق مكاسب لرأس المال البشري والحفاظ على سمعتهم، وعلى الرغم من أن هذه الإجراءات قد يترتب عليها أثراً سلبيًا على قيمة الثركة مستقبلاً Malmendier \& Tate, 2007; Francis et al. 2008; Petrou \& Procopiou, 2016) التورط المحتمل للمديرين في ممارسات التلاعب بالأرباح لا يمكن أن يتم بمعزل عن التحليل الذي أجرته لجنة Commission (COSO) Committee of Sponsoring Organizations of the Treadway المالية الاحتيالية لعدد من الثركات المقيدة بالبورصة الأمريكية اتضح تورط فريق الإدارة العليا في معظم حالات

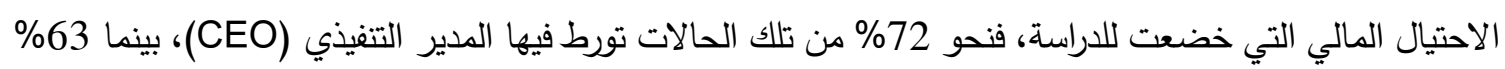

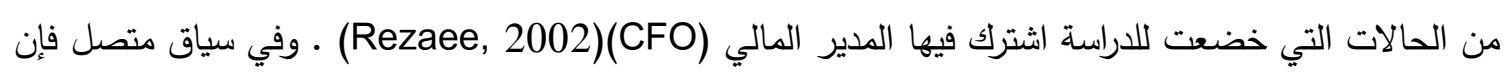
دراسة استقصائية أخرى (Graham, Harvey, \& Rajgopal, 2005) على عينة من 401 مدير مالي خلص من خلالها إلى عدة حقائق منها أن 78\% من المديرين في عينة الدراسة اعترفت بتفضيلها بالتتخل في العمليات التثغيلية

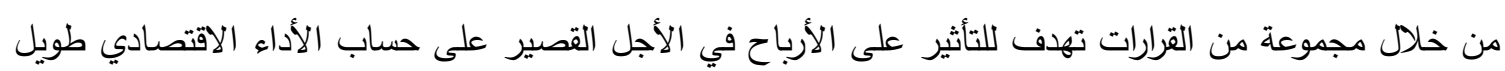

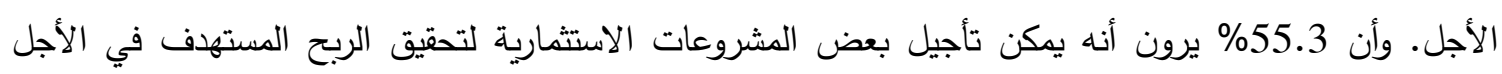
القصير ، ولو على حساب قيمة الشركة في الأجل الطويل.

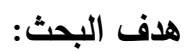

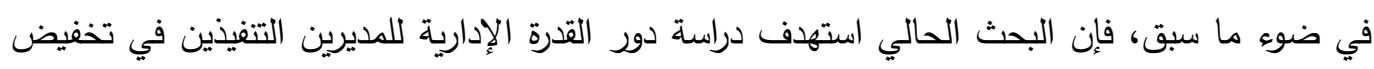

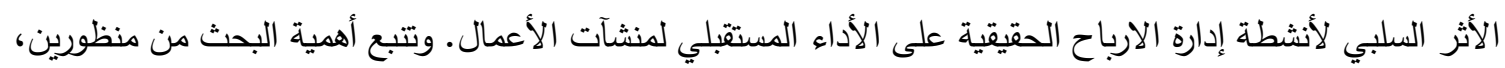

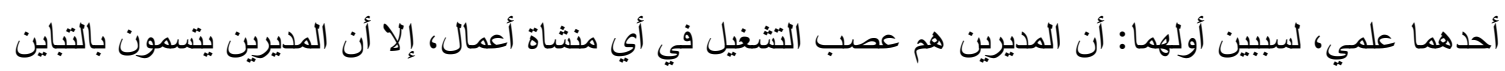

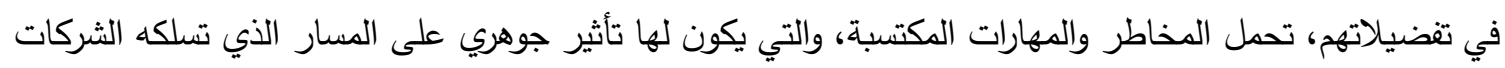

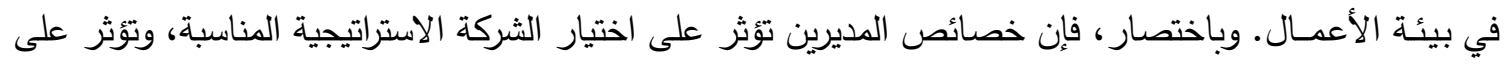

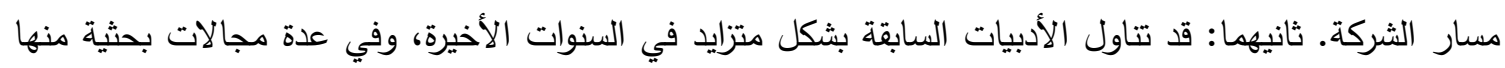
المحاسبية والاقتصاد والتمويل فحص تأثير الخصائص الإدارية على قرارات الثركات ونتائجها، مثل سياسات الاستثمار

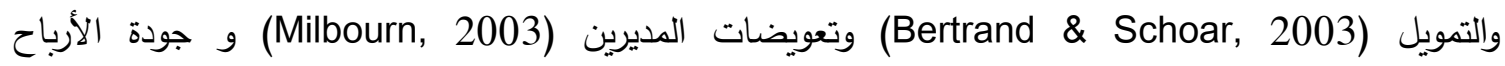
و (Baik et al., 2011; Bamber et al., 2010) و تتبؤات الإدارة بالأرباح (Bemerjian et al., 2013) تمهيد الأرباح (Baik et al., 2017). وتعد الدراسة الحالية امتدادا لهذا الاتجاه في الأدبيات حول دور القدرة الإدارية 
كعامل اقتصادي مؤثر على نتائج الشركات. أما الأهمية الأخرى تطبيقية، والتي تقسم إلى أهمية مكانية، فبيئة التطبيق

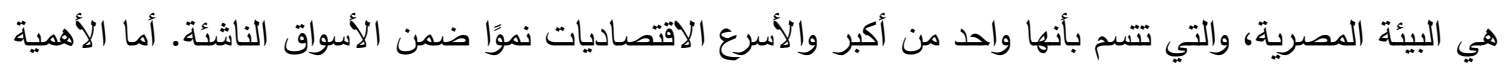
الثانية وهي الأهمية الزمنية، حيث ستغطي الدراسة السنوات من 2005 إلى 2015. خطة البحث:

ولتحقيق هدف البحث، فإن الجزء التالي من البحث تم تتظيمه على النحو التالي، أولاً " الدراسات السابقة

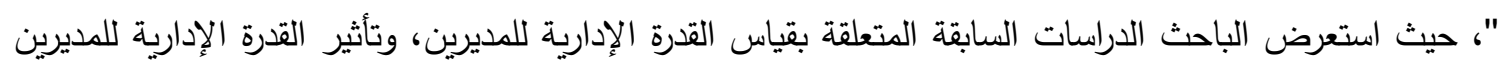

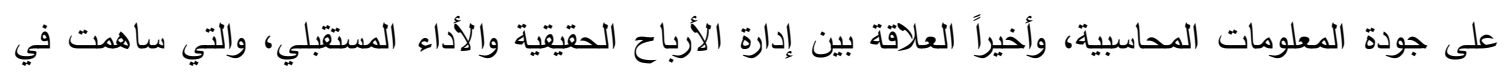

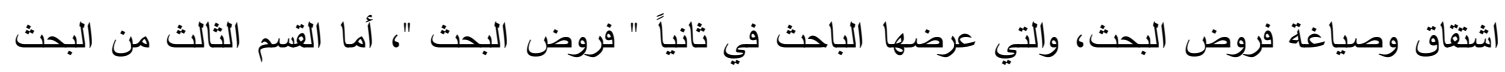

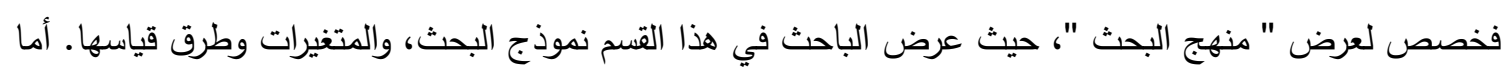
رابعاً " عينة البحث والإحصائيات الوصفية " يتعرض الباحث في هذا القسم لعينة البحث والوصف الإحصائي للبيانات ومصفوفة الارتباط بين المتغيرات. والقسم الخامس خصص لـ" النتائج "، وعرض الباحث في هذا القسم نتائج التحليل

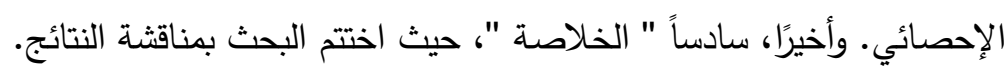

أولاً: الاراسات السابقة يتبنى المديرون أساليب متباينة في إدارة شركاتهم، فنجدهم مختلفين في تفضيلاتهم المحاسبية، وخيارات الإفصاح،

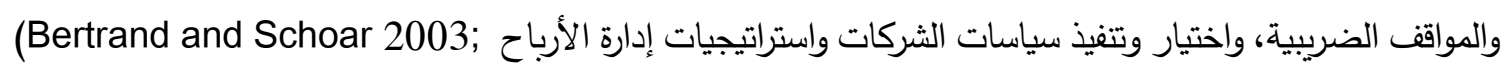
Bamber et al. 2010; Dyreng et al. 2010; Ge et al. 2011; Graham et al. 2012) الاختلافات نتيجة للخصائص الثخصية للمديرين مثل العمر ، والتعليم، والقدرات الكامنة، والميل إلى تحمل المخاطرة، والمعتقدات الفردية، والخبرة الحياتية، والخلفية المهنية، والاتصالات، والمهارات الثخصية، ولفئ، ومهارات التتفيذ 2010; Malmendier et al. 2011; Graham et (Bertrand and Schoar 2003; Bamber et al. al. 2012; Kaplan et al. 2012)

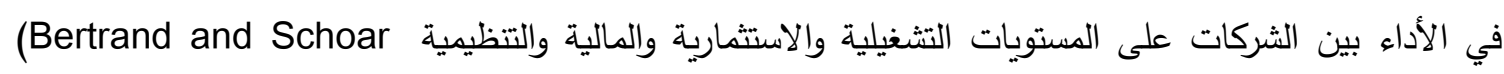
ذات المات 2003; Jian and Lee 2011; Malmendier et al. 2011)

$$
\text { ذات الصلة إلى ثلاثة أقسام على النحو التالي: }
$$

الحديث عن القياس الكمي لخصائص المديرين بما فيها المهارات والقدرة والنمط الإداري تحول مع الدراسة

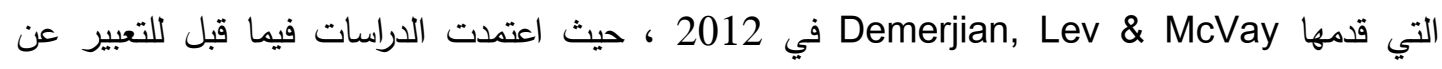
الخصائص الإدارية للمديرين على عدة مقاييس بديلة (Proxies)، مثل معدل دوران المدير التتفيذي (CEO)، وشهرة المدير التتفيذي (CEO) في وسائل الأعلام والتي في مجملها عبارة عن القدرة الإدارية للمديرين ببدائل اختزلت فقط في الددير التتفيذي فقط دون سواه من طاقم الإدارة العليا، والتي تؤثر على الأداء ونواتج الأعمال. أما عن مؤشر القدرة الإدارية (DEA score) الذي قدمه (Demerjian, et al. لقياس القدرة الإدارية للمديرين بناء على كفاء استغلال المديرين للموارد المتاحة وتحقق أعلى مقدار من المخرجات مقارنة بالمديرين

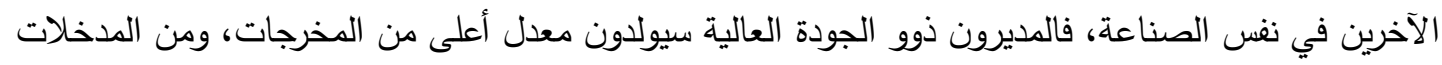
أو الموارد المتاحة، ومن ثم يتمتعون بكفاءة أعلى في استخدام الموارد المتاحة، وذلك بالمقارنة بالمديرين الأقل 
كفاءة في إدارة الموارد في نفس الصناعة والذين يحققون نواتج أقل أو نواتج عكسية. وبشكل أكثر تحديدا، فان كفاءة المديرين الشركات تتحدد داخل كل صناعة بمقارنة المبيعات التي تولدها كل شركة (المخرجات)، وبذلك فإنه يركز مؤشر القدرة الإدارية (DEA score) على المهارات الإدارية والتشغيلية الإدارية للمديرين. وقد أسس (2012) مemerjian, et al مؤشر القدرة الإدارية (DEA score) على ملتى مرحلتين، المرحلة

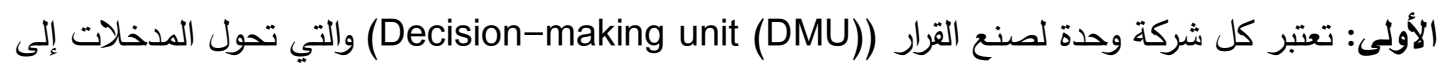
مخرجات، فالمدخلات هي الموارد المتاحة التي تستخدمها الشركة لتوليد تلك المخرجات - وذلك على ترتئ تُكيب عرضهم في المعادلات - وهما: تكلفة السلع المباعة، والمصروفات البيعية والإدارية، وصافي القيمة الدفترية للممتلكات والمعدات والآلات، وصافي عقود الإيجارات التشغيلية، وصافي نفقات البحث والتطوير ، الثهرة المشتراة نتيجة عمليات الاستحواذ، الأصول غير الملموسة الأخرى. تستخدم تلك المدخلات لتوليد المخرجات أو الإيرادات. وباستخدام تحليل مغلف البيانات Data Envelopment Analysis (DEA) يتم تقييم الكفاءة الكلية للثركة، تهيت والتي تولد تقديرا لكفاءة استخدام المديرين لموارد شركاتهم وتحويلها إلى مخرجات أو إيرادات وهي المنهجية القائمة

$$
\text { Firm Efficiency }=\frac{\sum_{i=1}^{s} u_{i} y_{i k}}{\sum_{j=1}^{m} v_{j} x_{j k}}
$$

ونواتج تحليل مغلف البيانات Data Envelopment Analysis (DEA) لكل صناعة بثكل سنوي يحدد الكفاءة الكلية للشركة Total firm efficiency والتي تتراوح قيمتها ما بين الواحد الصحيح وهي الشركات

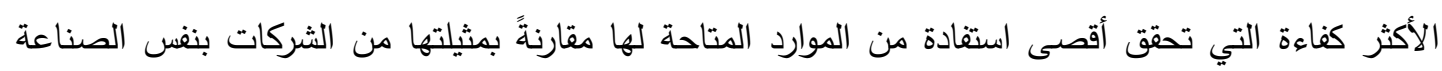
والقيمة صفر وهي الشركات غير ذات الكفاءة. والكفاءة الكلية للشركة التي سبق الإشارة اليها هي ناتج التفاعل بين موارد الثركة وإمكانياتها وإدارة تلك الموارد، ولا يمكن بأي حال من الأحول أن ينسب مستوى الكفاءة الكلية إلى القدرة الإدارية فقط أو موارد الشركة الثانج

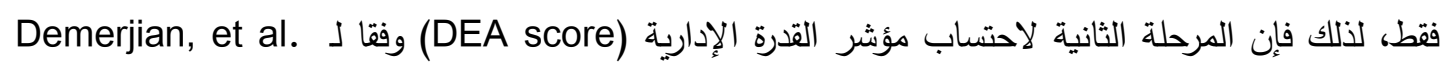
(2012) استبعاد تأثير بعض الخصائص الثركة المؤثرة على درجة الكفاءة الكلية الثركة التي تم الحصول عليها من الخطوة السابقة. وهي مجموعة من الخصائص أو العوامل والتي قد تعزز أو تعرقل أداء المديرين.

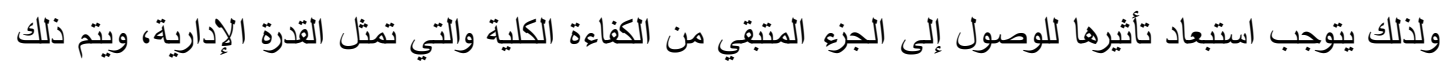

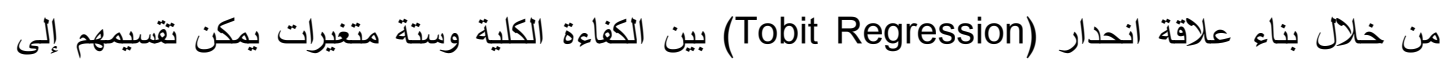
مجموعتان، المجموعة الأولى هي مجموعة العوامل المعاونة للإدارة، وهما حجم الثركة فالثركات الكبيرة لديها لئاء

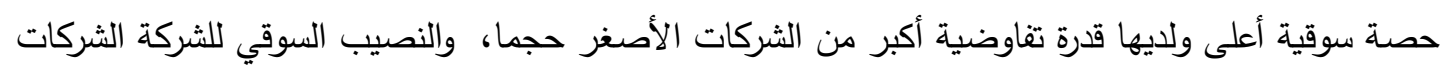

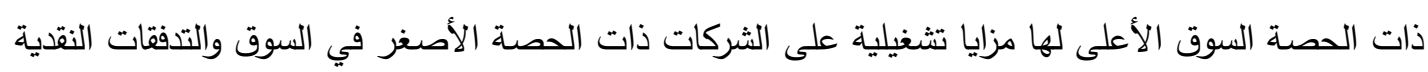
الحرة الموجبة عندما يكون لدى الشركات تدفق نقدي حر موجب أعلى، ويشير ذلك إلى أنها قادرة على اختيار

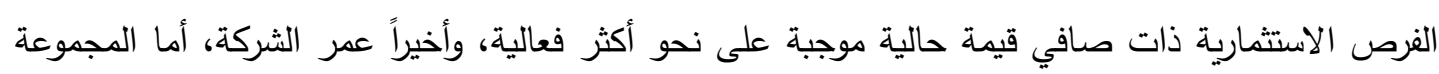

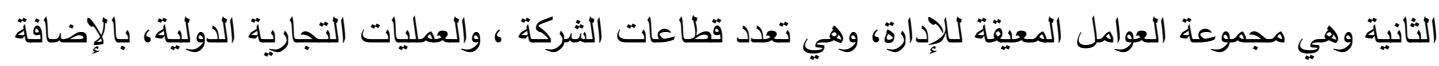

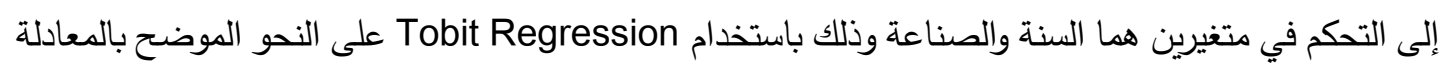

رقم (3): 
Firm Efficiency $=\beta_{0}+\beta_{1} \operatorname{Ln}($ Total Assets $)+\beta_{2}$ MarketShare $+\beta_{3}$ PositiveFreeCashFlow $+\beta_{4} \operatorname{Ln}($ Age $)$
$+\beta_{5}$ BusinessSegmentConcentration
$+\beta_{6}$ ForeignCurrencyIndicator + Year Indicator $+\epsilon$

وعقب عزل تأثير العوامل الداعمة للإدارة والعوامل المعوقة لعمل الإدارة وتأثير السنة والصناعة من الكفاء الكلية المحسوبة، فإن بواقي Residual علاقة الانحدار السابقة يمكن أن تتسب إلى القدرة الإدارة للمديرين

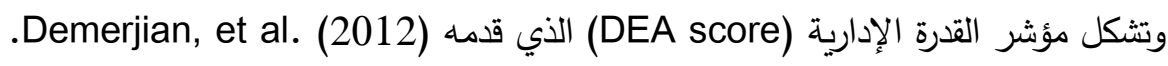

وقد استخدم مؤشر القدرة الإدارية (DEA score) من قبل العديد من الدراسات الحديثة سيتعرض لها

García-Meca الباحث ذات الصلة لاحقاً- ولكن الدراسة الهامة نظراً لخصوصية قطاع التطبيق هي دراستة \& \&arcía-Sánchez (2017) لاختبار تأثير القدرة الإدارية للمديرين على جودة التقارير المالية بالتطبيق

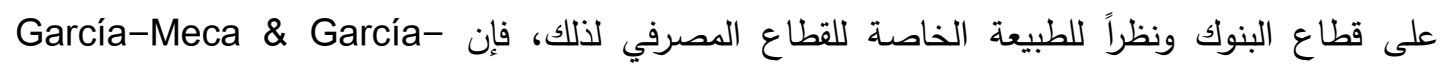

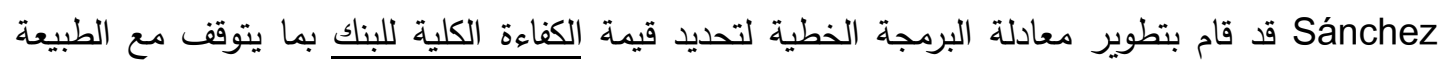

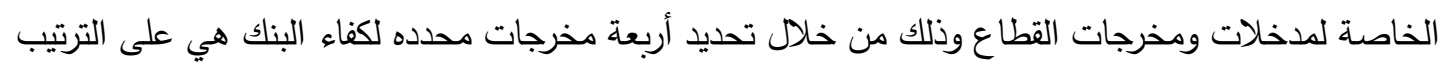

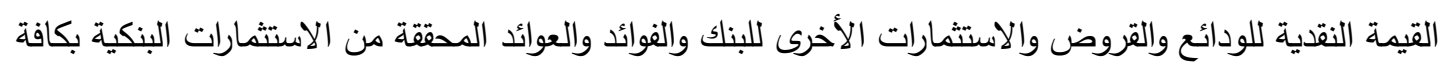

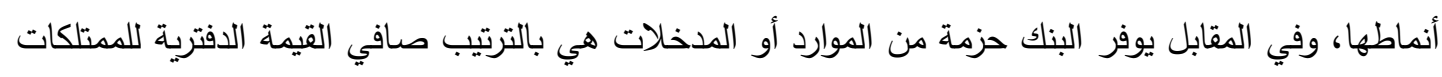

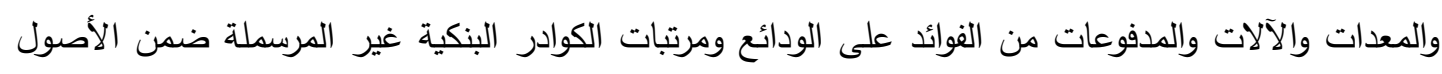
غير الملموسة للبنك، وتكون المعادلة بالثكل التالي: $\max \theta=\frac{u 1 \text { Deposits }+u 2 \text { Loans }+ \text { u3Investment }+ \text { u4IntInco }}{v 1 P P E+v 2 \text { Int }+v 3 \text { Labor }+v 4 \text { IntExp }+v 5 \text { RentalExp }}$

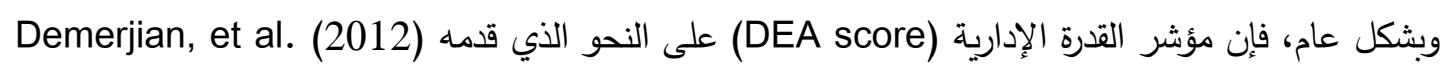
لا يستبعد تأثير جميع خصائص للشركة التي تؤثر على كفاءة الشركة مثل هيكل حوكمة الشركات، المراجع

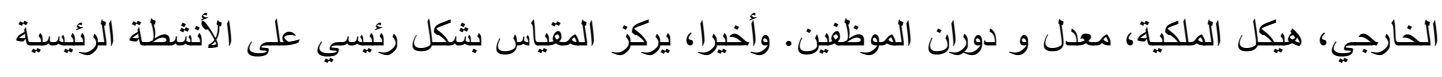

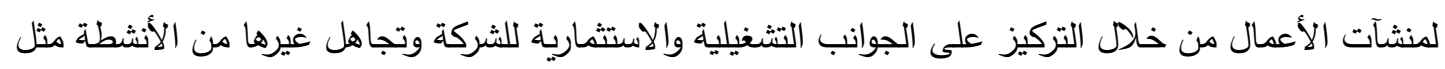

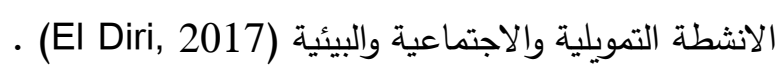

2) تأثير القدرة الإدارية للمديرين على جودة المعلومات المحاسبية:

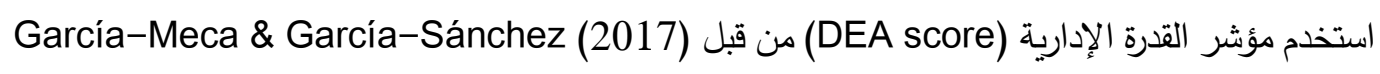
لاختبار تأثير القدرة الإدارية للمديرين على جودة التقارير المالية بالتطبيق على قطاع البنوك في 159 دولة من خلال تحليل قطاعي زمني Panel Data يغطي السنوات من 2004 إلى 2010 2010، فالمديرين قد يستخدمون

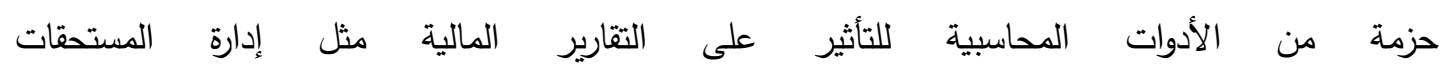


أو التدخل من خلال عمليات تمهيد الأرباح بناء على مجموعة من العوامل مثل تصرفاتهم أو مواقفهم الثخصية

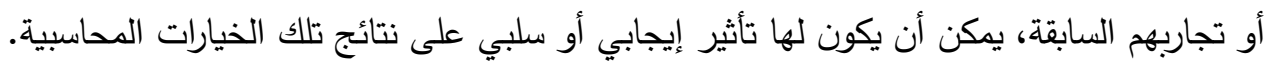

Earnings quality أما عن جودة التقارير المالية فقد تم التعبير عنها من خلال جودة الأرباح

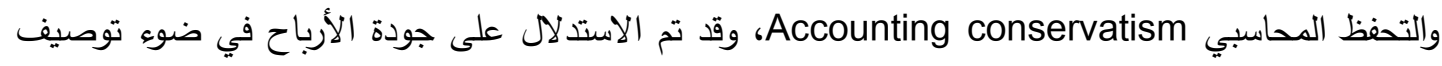

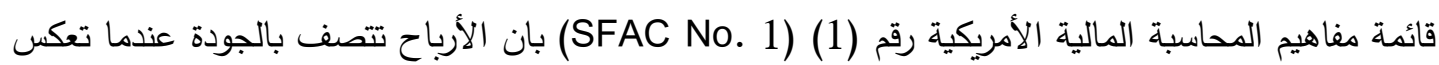

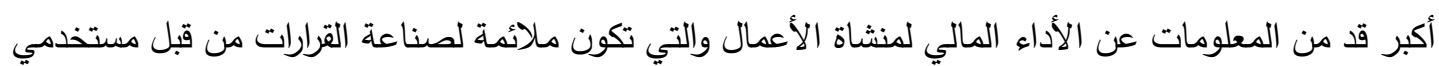

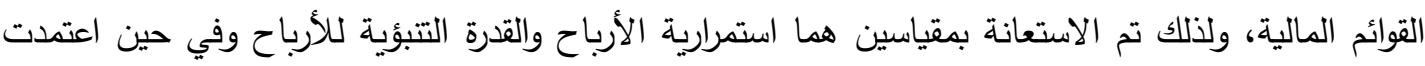

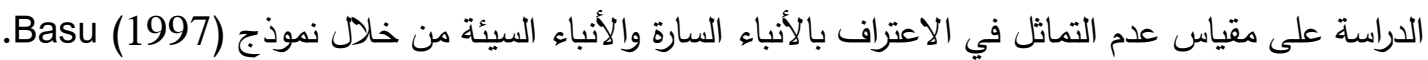

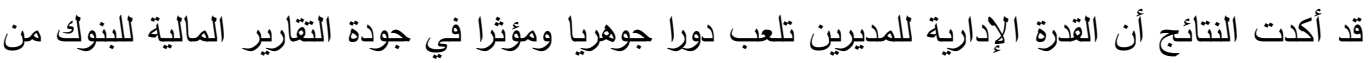

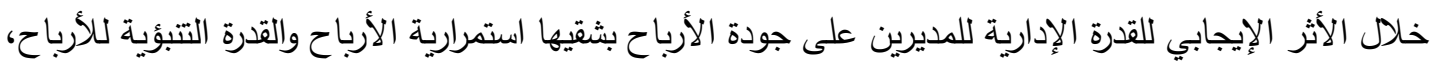
ولاسيما فيما يخص التحفظ المحاسبي من الخسائر المحتملة، وخلاصة القول أن استحواذ البنوك على كوادر إدارية ذات كفاءة عالية يخفض من احتمالات السلوكيات الانتهازية من جانب المديرين للتلاعب بالأرباح. وفي سياق متصل جاءت دراسة (2017) Baik, Brockman, Farber, and Lee لفحص العلاقة بين القدرة الإدارية للمديرين وجودة البيئة المعلوماتية (جودة الافصاح) للشركات، فالمديرون من ذوى القدرات الإدارية

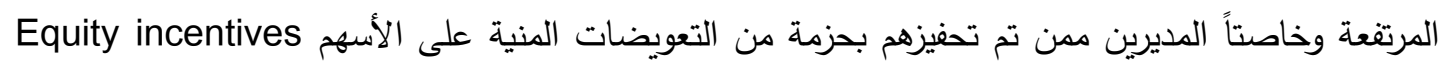
يتولد لديهم قدرة أعلى على إطلاع أسواق رأس المال بالتغيرات في البيئة الاقتصادية للشركة وتحمين البئية البئة البئة المعلوماتية وزيادة شفافيتها، وهو الأمر الذي ينعكس على مشكلة عدم تماثل المعلومات بين الإدارة والمستثمرين بالتخفيض، وذلك حتى في ظل ضعف نظام الحوكمة بالثركة ممثلة في ضعف الملكية المؤسسية واستقلالية مجلس الإدارة معا يفضل المديرون تحسين جودة الإفصاح بالشركة.

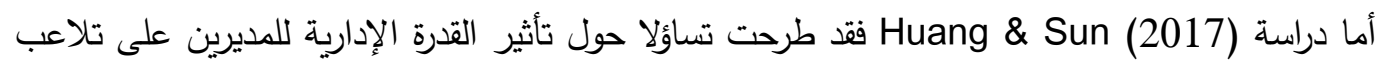
الإدارة في الأرباح من خلال التحكم في توقيت وقيمة الأنشطة الحقيقة، وقد خلصت الدراسة إلى وجود على علاقة

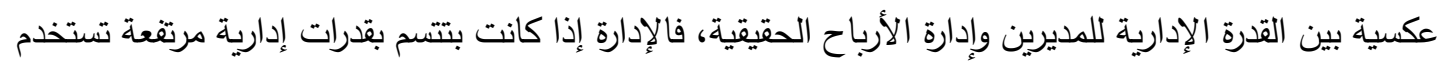

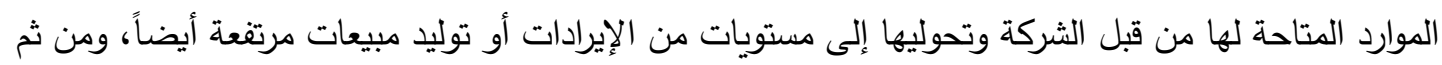
لا تضطر الإدارة الانخراط في أنشطة إدارة الأرباح الحقيقية. بالإضافة إلى إدراك المديرين إلى الأثر السلبي لتلكاتك

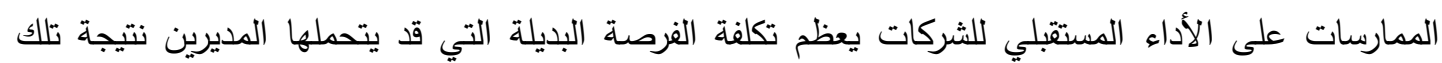
الممارسات، مما قد يؤثر على سمعتهم في بيئة الأعمال، ولذلك فإن المديرين من ذوي القدرات الإدارية يفضلون

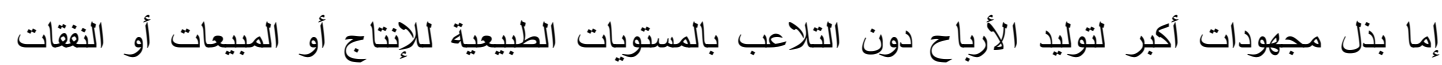

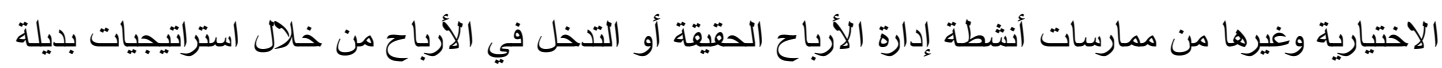

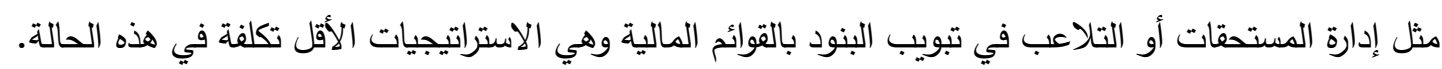
وفي ذات السياق جاءت دراسة Demerjian, Lewis, Lev \& McVay (2013) لفحص العلاقة بين القدرة الإدارية للمديرين وجودة الأرباح، فقد اهتمت العديد من الدراسات باستقصاء تأثير خصائص الثركات مثل

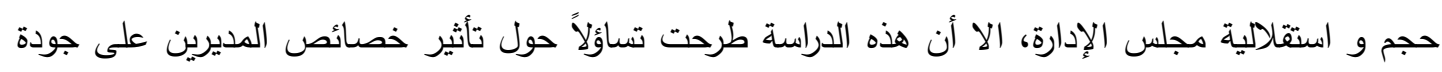

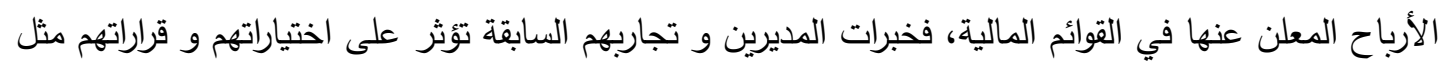


Demerjian, et al. (2013a) المتعلقة بالاستحواذ أو الانخراط في البحوث التطوير ، لذلك فقد اهتمت دراسة بفحص تأثير القدرات الإدارية للمديرين على أربعة خصائص للأرباح المحاسبية (تعديل الأرباح، استمرارية

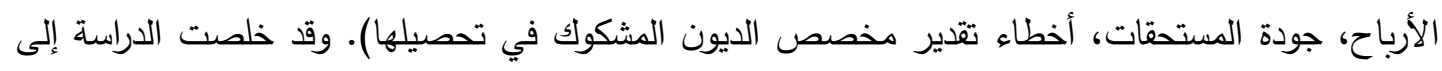

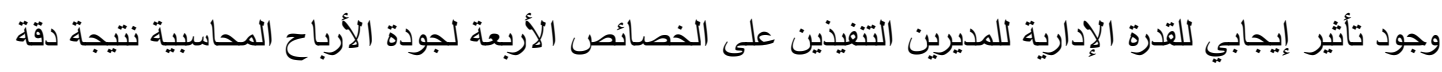

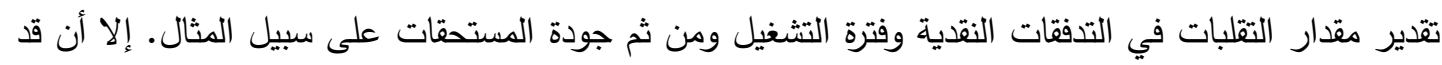

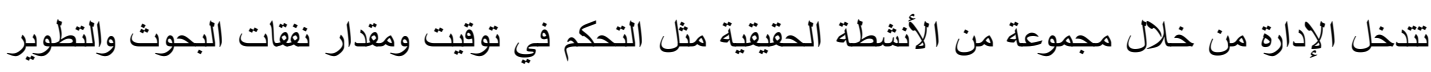
وقرارات الاندماج والاستحواذ وهي القرارات التي قد تخفض من جودة المستحقات ليس نتيجة السلطة التقديرية للمديرين ولكن نتيجة لطبيعة النظام المحاسبي ذاته وهو الأثر الذي لا يمكن للمديرين بما يمتلكونه من قدرات إدارية تخفيضة أو تلاشيه. ويضيف Demerjian, Lewis, Lev \& McVay (2013b) أن أساليب إدارة الأرباح الحقيقية هي أكثر تكلفة من حيث تأثيرها السلبي على المبيعات المستقبلية مقارنة بأساليب إدارة الأرباح القائمة على استخدام المستحقات، وبالتالي يفضل المديرون ذوو القدرات الإدارية الأعلى أساليب إدارة الأرباح

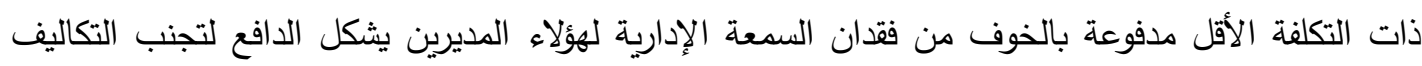

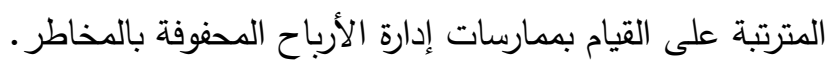

3) تأثير إدارة الأرباح الحقيقية على الأداء المستقبلي لمنشآت الأعمال: إن الإدارة قد تتدخل من خلال إدارة الأنثطة الحقيقية للتحكم في التقارير المالية، ولاسيما في نتائج الأعمال

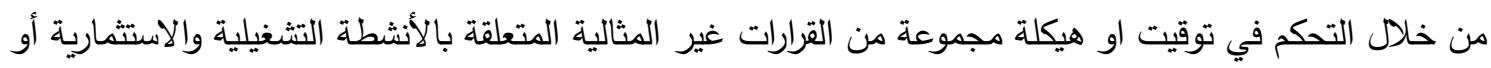

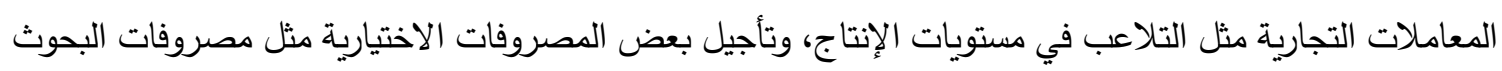
والتطوير، والتلاعب في حجم المبيعات، وتقديم خصومات للأسعار أو تغيير سياسة البيع الآجل، وهيكلة المعاملات

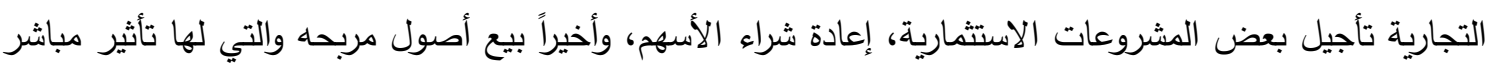
على التدفقات النقدية وبالتالي في الأرباح بدافع من رغبة المديرين في تضليل أصحاب المصلحة حول الأداء الحقيقي للشركة. وفي سياق الدراسة المسحية التي قام بها Graham et al والتي تمت على عينة من كبار الدديرين

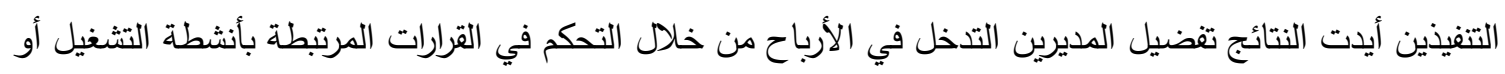

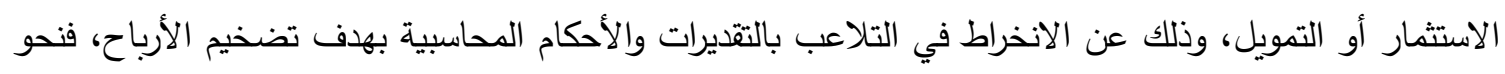
(80\%) من المديرين يفضلون تخفيض النفقات الاختيارية مثل مصروفات البحوث و التطوير و مصروفات الدعاية

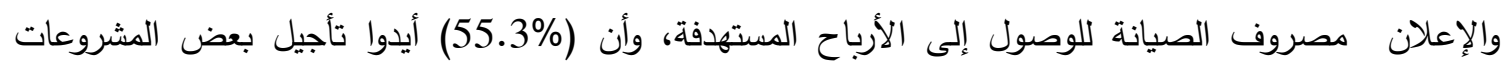
الاستثمارية في سبيل الحفاظ على الأرباح الحالية ولو على حساب القيمة المستقبلية للشركة.

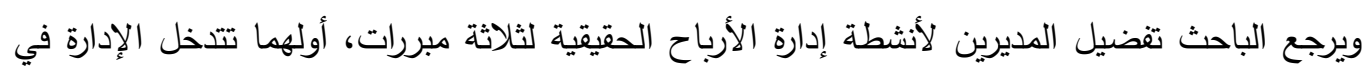
الأنثطة الحقيقية الاعتيادية خلال دور التثغيل دون الانتظار لنهاية دورة التشغيل كما هو الحال في إدارة الأرباح

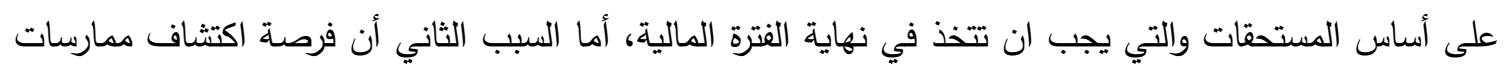

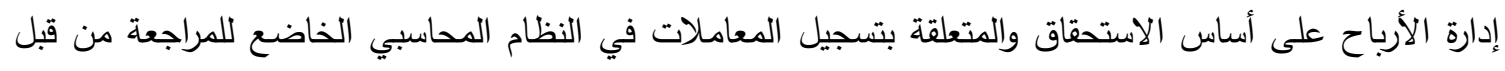

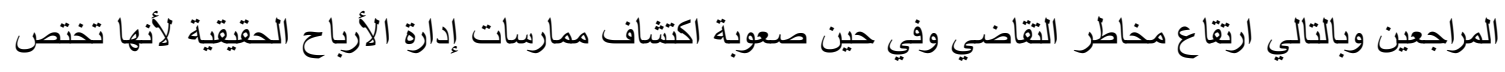
بطريقة إدارة الأنشطة نفسها من قبل المديرين وليس طريقة تسجيلها، ومن ثم انخفاض مخاطر التقاضي. لذلك يفضل 
المديرين في الكثير من الأحيان التتخل في الأنثطة نظراً لأنها الأقل تكلفة. أما السبب الثالث والأخير هو أن إدارة

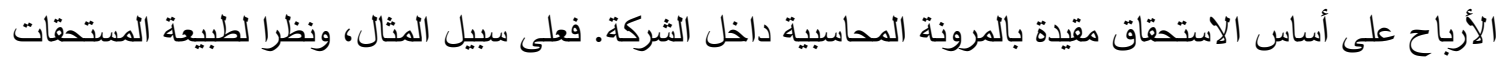

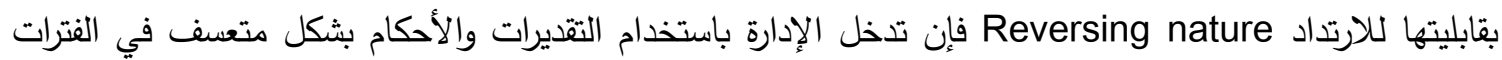
السابقة تمنعها من وضع تقديرات وأحكام مماثلة في الفترات اللاحقة.

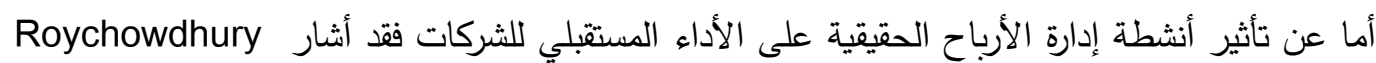
(2006, P.38)

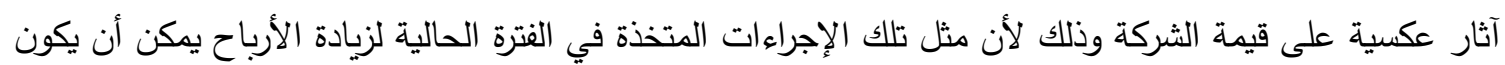

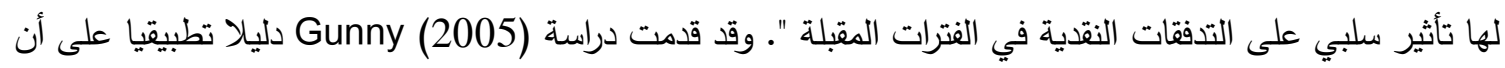

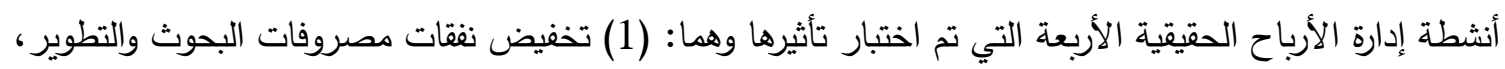

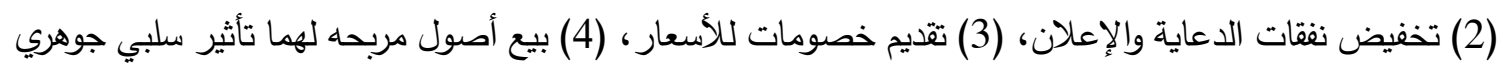

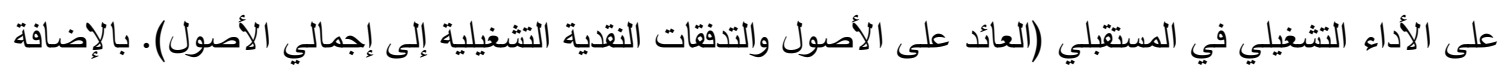

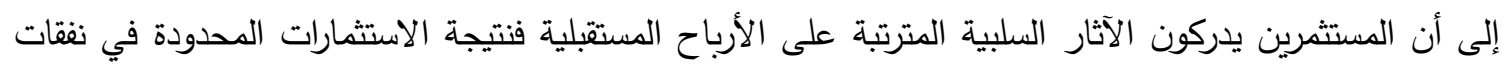

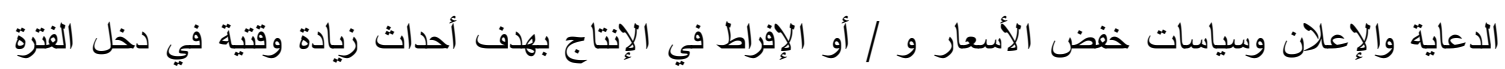
الحالية. ويضيف Abernathy, Beyer, and Rapley (2014) أن السياسة قصيرة النظر من جانب المديرين بالتذخل في الأرباح

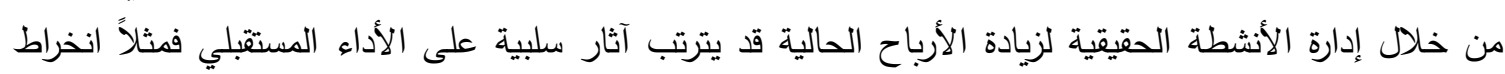

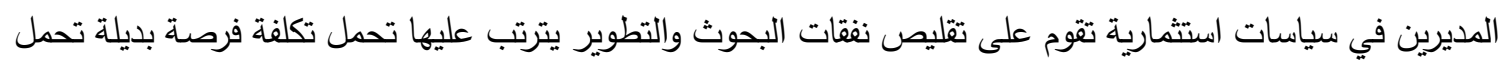
مردودات عكسية على الأداء في المستقبل. وعلى النقيض مما سبق جاءت نتيجة دراسة Gunny (2010) يمكن للمديرين المشاركة في إدارة الأنشطة

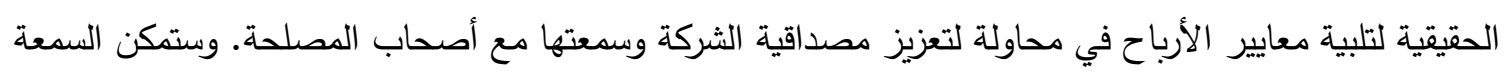

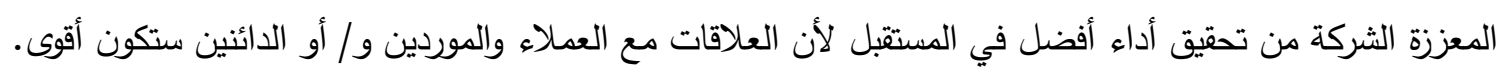
وبذلك، يمكن للمديرين استخدم إدارة الأنشطة الحقيقية لمجرد تلبية المعايير كوسيلة فقط لإرسال إثارات للسوق بالعائدات المستقبلية. وأخيراً فإن دراسة Huang \& Sun (2017) قدمت دليلا تطبيقيا على وجود علاقة عكسية بين إدارة الأنثطة الحقيقية والأداء المستقبلي يمكن تخفيض وطأتها من خلال القدرة الإدارية للمديرين مفسراً تلك النتيجة بمبررين: المبرر الأول القدرة الإدارية للمديرين تمنحهم فهم أفضل للشركات التي يقومون بإداراتها وبيئة عمل شركاتهم،

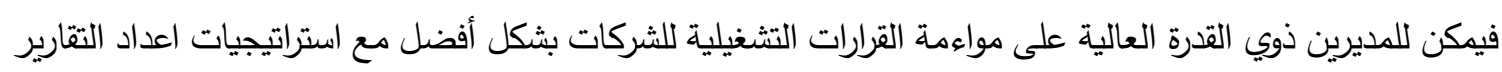

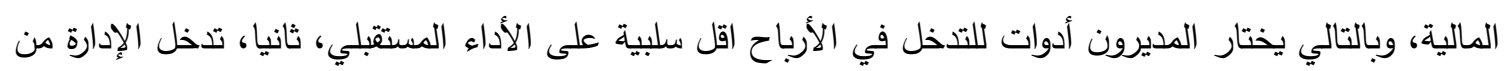

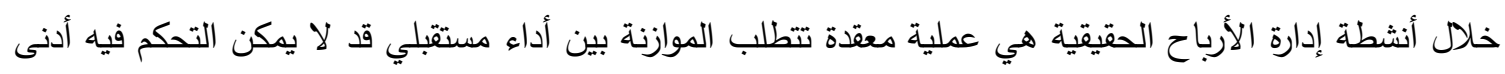

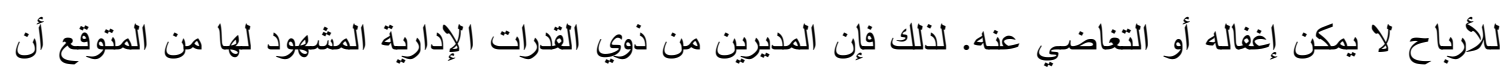
تكون قادرة على تقدير الأرباح المستقبلية وتحديد أوجه القصور في وقت سابق، وبالتالي قدرة المديرين المبكرة من التنخل بالخيارات المحاسبية لتخفيض كلفة التتخل بإدارة أنثطة إدارة الأرباح الحقيقية. 


$$
\text { ثانياً فروض البحث: }
$$

يمكن تفسير تأثير القدرة الإدارية للمديرين على العلاقة المتوقعة بين إدارة الأرباح الحقيقية وأداء منشآت

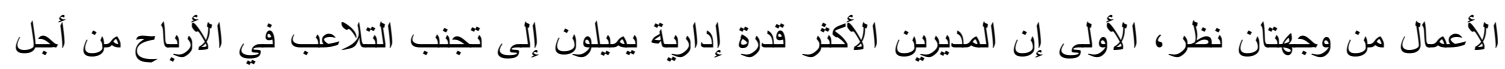

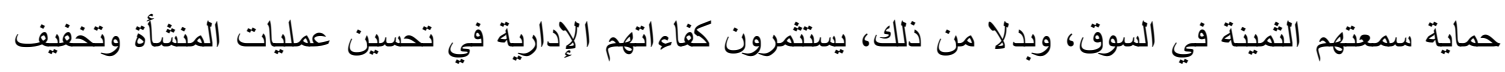
حدة الأزمات المالية التي تتعرض لها، وبهذا المعنى، ترتبط القدرة الإدارية الأفضل بجودة عالية من الأرباح للسماح

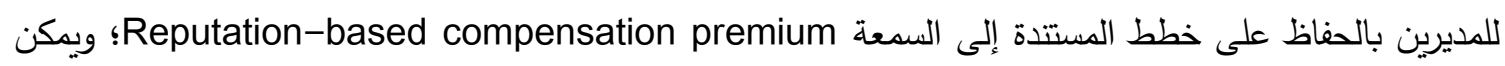
تحديد عدة عواقب إيجابية للقدرة الإدارية فمن المتوقع أن يظهر المديرون ذوو القدرات الادارية عددا أقل من التعديلات

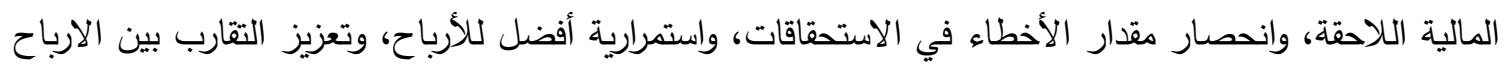
و التدفقات النقدية التثغيلية. وقد يصبح دورهم أكثر وضوحا في المستقبل نظرا لارتباطهم عموما بتحسين أداء الأعمال

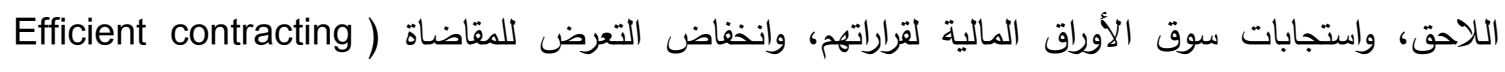
(hypothesis). أما وجهة النظر الثانية، قد يستثر المديرون ذوو القدرات الإدارية مهاراتهم العالية في استخدام المزيد

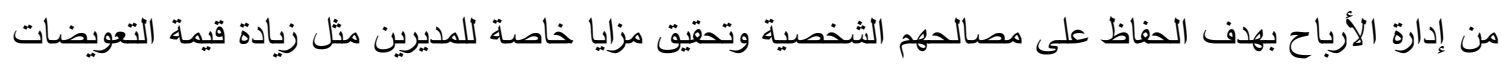

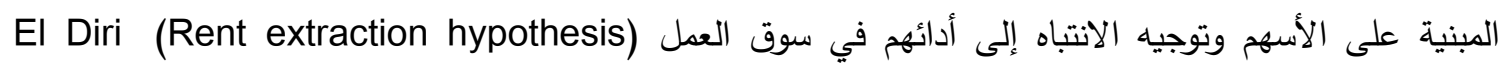

وفي ضوء ما سبق، يمكن للباحث استخلاص فروض البحث والتي يمكن استخلاصها من مراجعة الأدبيات وصياغتها في شكل فرض من طرفيين معبراً عنها في صيغة العدم على النحو التالي: الفرض الأول (H) لا توجد علاقة بين القدرة الإدارية للمديرين والأنثطة الحقيقية لإدارة الأرباح.

الفرض الثاني (H)

لا يوجد تأثير للقدرة الإدارية للمديرين على العلاقة بين والأنشطة الحقيقية لإدارة الأرباح والأداء المستقبلي

$$
\text { ثالثاً منهج البحث: للشركات. }
$$

في ضوء الدارسات السابقة يمكن للباحث عرض فروض ومتغيرات الدراسة المستهذف اختبارها من خلال الثكل التالي: 
(1) - (الثكل رقم (1)

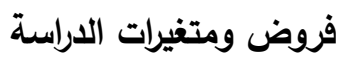

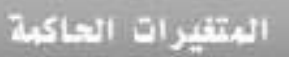

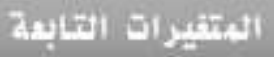

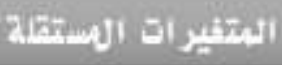

\section{$\mathrm{H}_{1}$}

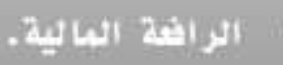

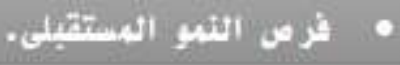

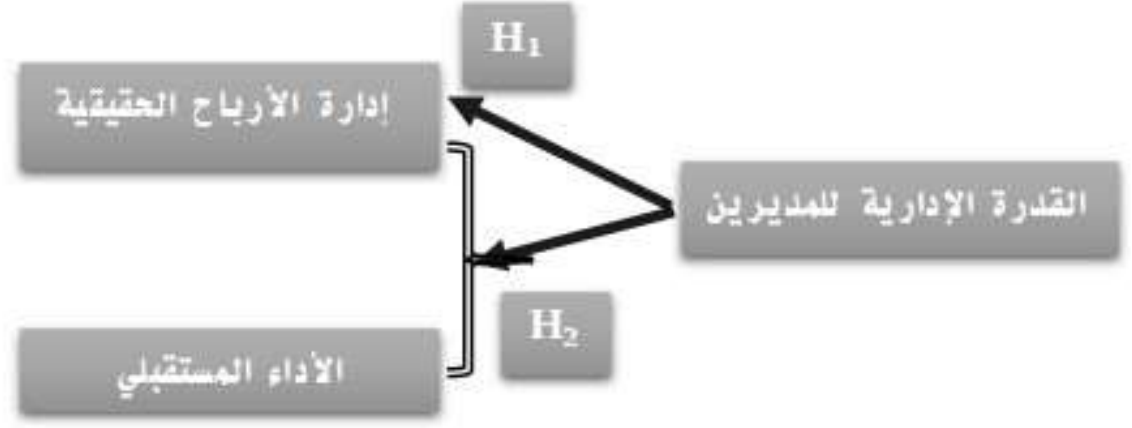

يعرض الباحث في السطور التالية المتغيرات محل الداسة وطرق قياسها:

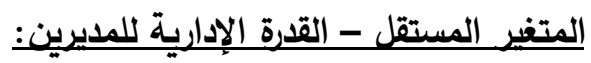

استخدم الباحث مؤشر القدرة الإدارية (DEA score) الذي قدمه (2012) Demerjian, et al لقياس القدرة Data Envelopment Analysis الإدارية للمديرين على مرحلتين، المرحلة الأولى وباستخدام تحليل مغلف البيانات (DEA) " يتم تقييم الكفاءة الكلية للشركة للعلاقة بين الدخخلات إلى مخرجات لكل شركة في كل صناعة وبشكل سنوي من خلال المعادلة رقم (4) التالية:

$$
\max \theta=\frac{\text { Sales }}{v_{1} C O G S+v_{2} S G \& A+v_{3} P P E}
$$

المخرجات في المعادلة رقم (4) هي الإيرادات أو المبيعات Sales، أما المدخلات هي تكلفة السلع المباعة

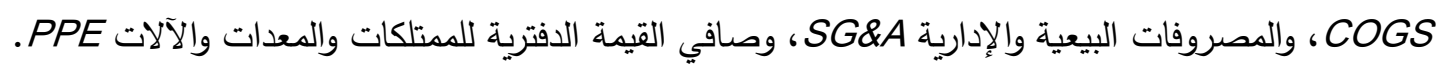

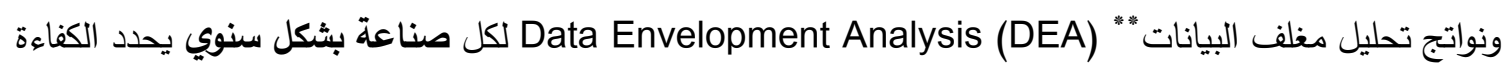
الكلية للشركة Total firm efficiency، والمرحلة الثانية لاحتساب مؤشر القدرة الإدارية (DEA score) درجة الكفاءة الكلية وتحديد مؤشر القدرة الإدارية باستخدام Tobit Regression" على النحو الموضح بالمعادلة Press. 


$$
\begin{aligned}
\text { Firm Efficiency }= & \beta_{0}+\beta_{1} \operatorname{Ln}(\text { Total Assets })+\beta_{2} \text { MarketShare } \\
& +\beta_{3} \text { PositiveFreeCashFlow }+\beta_{4} \text { Ln }(\text { Age }) \\
& +\beta_{5} \text { ForeignCurrencyIndicator }+ \text { Year Indicators }+\epsilon
\end{aligned}
$$

حيث أن Firm Efficiency الكفاءة الكلية للشركة، (Ln(Total Assets لوغاريتم إجمالي الأصول، MarketShare PositiveFreeCashFlow

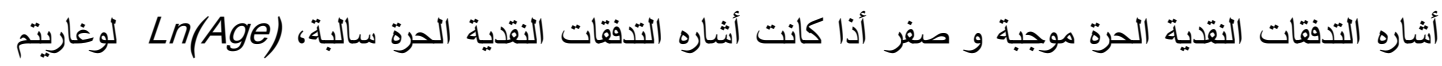
عمر الشركة، ForeignCurrency/ndicator متغير وهمي يأخذ القيمة واحد إذا حققت أرباح الشركة من العملات الأجنبية، وغير ذلك يأخذ القيمة صفر، Year Indicators متغير وهمي للسنة لكل شركة. بواقي (DEA علاقة الانحدار السابقة تتسب إلى القدرة الإدارة للمديرين وتثكل مؤشر القدرة الإدارية Residual

Demerjian, et al. (2012) الذي قدمه (score)

المتغيرات التابعة -إدارة الأرباح الحقيقية والأداء المستقبليذ

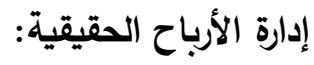

قد تتدخل الإدارة بالتحكم في التقارير المالية ولاسيما في نتائج الأعمال من خلال التحكم في توقيت او هيكلة

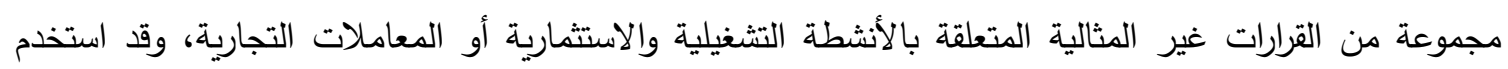

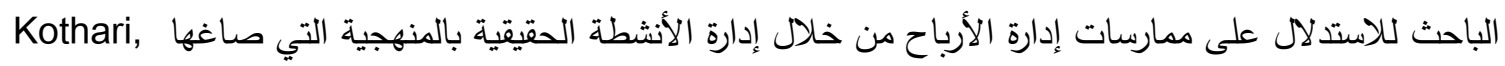

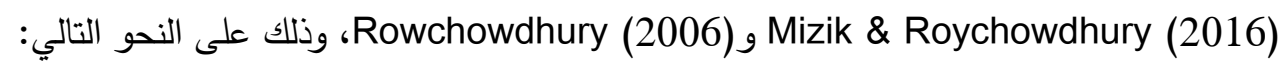
(1) التلاعب بالمبيعات-القيمة المطلقة التدفقات النقدية التثغيلية الغير العادية: تدخل الإدارة لزيادة

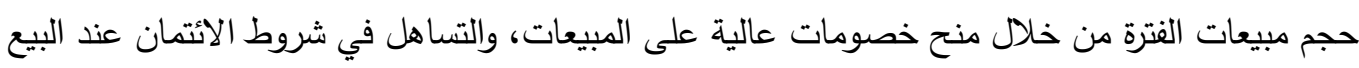
بالآجل مثل تخفيض معدل الفائدة على المبيعات الآجلة، زيادة فترة الائتمان الممنوحة عند البيع الآجل. وذلك من أجل نقل مبيعات العام القادم إلى العام الحالي الأمر الذي يؤدي إلى التضحية بالأرباح المستثبلية

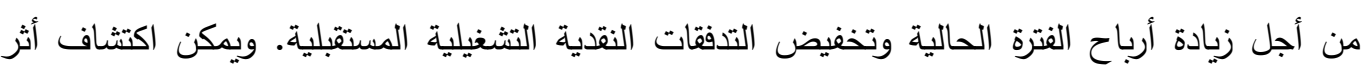
التلاعب في المبيعات وفقاً لمنهجية (2006) Rowchowdhury من خلال علاقة خطية بين التدفقات النقدية التشغيلية والتغير في المبيعات على مستوى كل قطاع لكل سنة من خلال النموذج التالي:

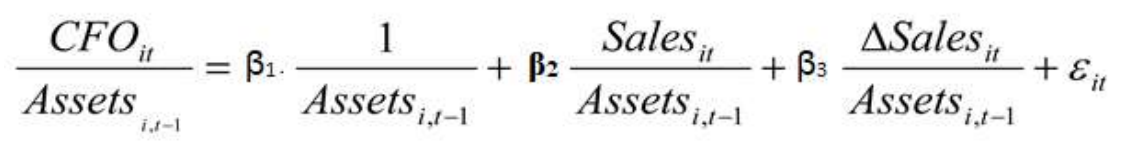

ثم يتم تحديد القيمة المطلقة التدفقات النقدية التشغيلية غير العادية ACFO التثغيلية المعادلة السابقة NCFO على النحو التالي: ACFOit = ((CFOit / Assetit-1) - NCFOit $) *-1$ (2) الإنتاج الزائد: إدارة الأرباح الحقيقية من خلال التحكم في الإنتاج، عن طريق زيادة حجم الإنتاج

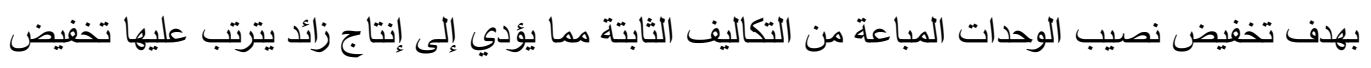


تكلفة البضاعة المباعة وبالتالي زيادة مجمل الربح. ويمكن اكتثاف أثر التلاعب في حجم الإنتاج وفقاً لهنهجية Rowchowdhury (2006 من خلال النموذج التالي:

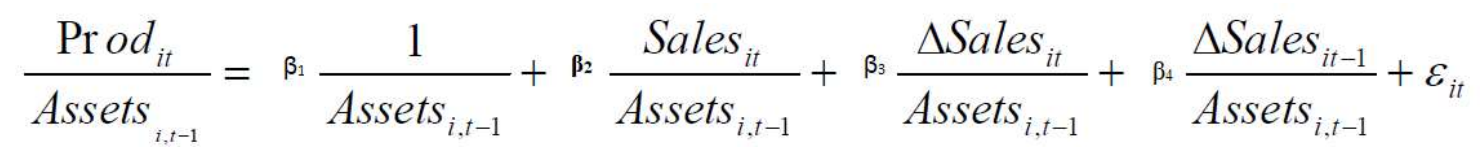

حيث إن: حجم الإنتاج Prodit هو محصلة تكلفة البضاعة المباعة والتغير في رصيد المخزون خلال السنة.

ثrodit / بالفرق بين حجم الإنتاج

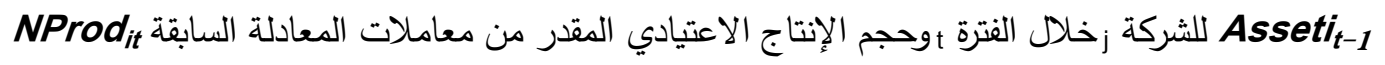
على النحو التالي: (1 - n

AProdit = ((Prodit / Assetit-1) - NProdit $) *-1$

(3) تخفيض النفقات الاختيارية: يمكن للشركة زيادة أرباحها أو تخفيضها من خلال التحكم في المصروفات

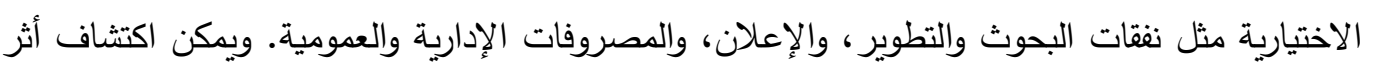

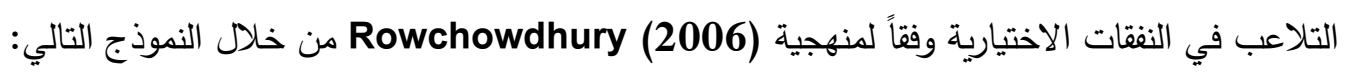
$\frac{\operatorname{DiscExp}_{i t}}{\text { Assets }_{i, t-1}}=\beta_{1} \frac{1}{\text { Assets }_{i, t-1}}+\beta_{2} \cdot \frac{\text { Sales }_{i, t-1}}{\text { Assets }_{i, t-1}}+\varepsilon_{i t}$

حيث إن: النفقات الاختيارية DiscExp هي محصلة المصروفات التثغيلية والمصروفات الإدارية خلا السنة.

ثم يتم تحديد القيمة المطلقة للنفقات الاختيارية غير العادي ADiscEXp بالفرق بين النفقات الاختيارية ل للشركة خلال الفترة t DiscExp / Assetit-1 المعادلة السابقة DiscExp على النحو التالي: AProdit = ((Prodit / Assetit-1) - NProdit $) *-1$

(3) تخفيض النفقات الاختيارية: يمكن للشركة زيادة أرباحها أو تخفيضها من خلال التحكم في المصروفات

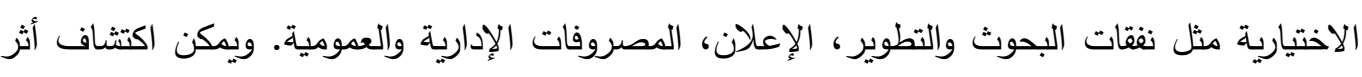
التلاعب في النفقات الاختيارية وفقاً لمنهجية (2006) Rowchowdhury من خلال النموذج التالي: $\frac{\operatorname{DiscExp}_{i t}}{\operatorname{Assets}_{i, t-1}}=\beta_{1} \frac{1}{\text { Assets }_{i, t-1}}+\beta_{2} \cdot \frac{\text { Sales }_{i, t-1}}{\text { Assets }_{i, t-1}}+\varepsilon_{i t}$

حيث ان: النفقات الاختيارية DiscExp هي محصلة المصروفات التثغيلية و المصروفات الادارية خلال

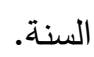


ثم يتم تحديد القيمة المطلقة للنفقات الاختيارية الغير عادي ADiscExp DiscExp / Assetit-1 المعادلة السابقة DiscExp على النحو التالي:

ADiscExpit $=(($ DiscExpit $\mid$ Assetit -1$)-$ NDiscExpit $) *-1$

الأداء المستقبلي: عبر الباحث عن الأداء المستقبلي من خلال معدل العائد على الأصول (ROA) والتدفقات النقدية

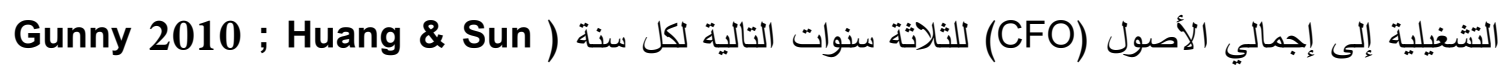

المتغيرات الحاكمة (العرضية):

يستخدم اصطلاح المتغيرات العرضية للإثشارة إلى المتغيرات المستقلة غير المرتبطة بأهداف الدراسة، وفي نفس الوقت يكون لها تأثيرا على المتغيرات التابعة التي تتطوي عليها الدراسة. ويري الباحث أن من العوامل الهامة

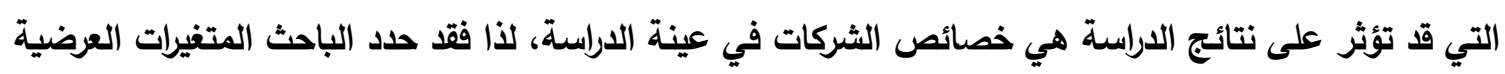
التالية وطربقة قياسها: نسبة الالتزامات طويلة الأجل إلى إجمالي الأصول. الرافعة

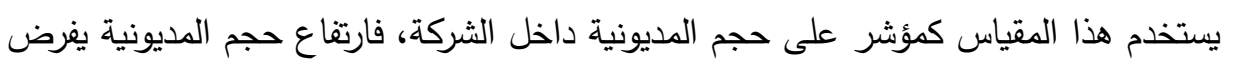

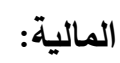

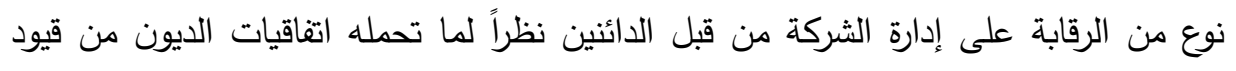
ومحددات.

حجم الثركة: اللوغاريتم الطبيعي للقيمة الدفترية لإجمالي الأصول. فالثركات الكبيرة الحجم تكون معرضة لتحمل تكاليف سياسية أكبر من صغيرة الحجم نظرا لوجود الاهول

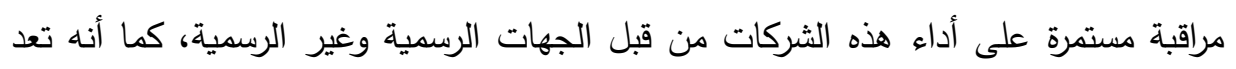

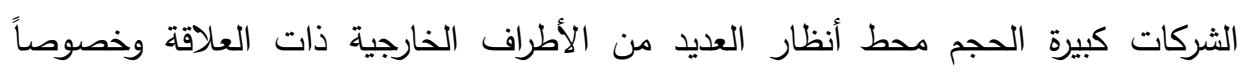
المستثمرين والمحللين الماليين.

وحتى يتمكن الباحث من اختبار الفرضين السابق عرضهما، يعرض الباحث نموذجي الانحدار محل الاختبار في

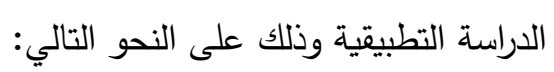

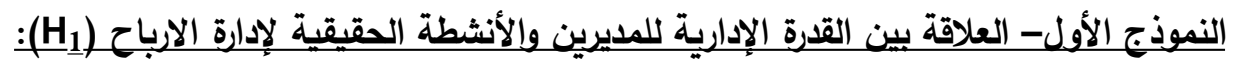
$\mathrm{RM}_{\mathrm{it}}=\beta_{0}+\beta_{1}$ DEAscore $_{\text {it }}+\beta_{2}$ Leverage $_{\text {it }}+\beta_{3}$ LogTotalAssets $_{\text {it }}+$ Year +Industry $+\varepsilon$ 
النموذج الثاني -تأثير القدرة الإدارية للمديرين على العلاقة بين الأنثطة الحقيقية لإدارة الأرباح والأداء المستقبلي للشركات (H)

$\mathrm{FP}_{\text {it }}=\beta_{0}+\beta_{1}$ DEAscore $_{\text {it }}+\beta_{2} \mathrm{RM}_{\mathrm{it}}+\beta_{3}$ DEAscore* RM $_{\text {it }}+\beta_{4}$ Leverage $_{\text {it }}+$ $\beta_{5}$ LogTotalAssets $_{\text {it }}+$ Year +Industry+ $\varepsilon$

الجدول التالي يتضمن تعريف المتفيرات المستخدمة:

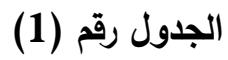

توصيف متغيرات الدراسة

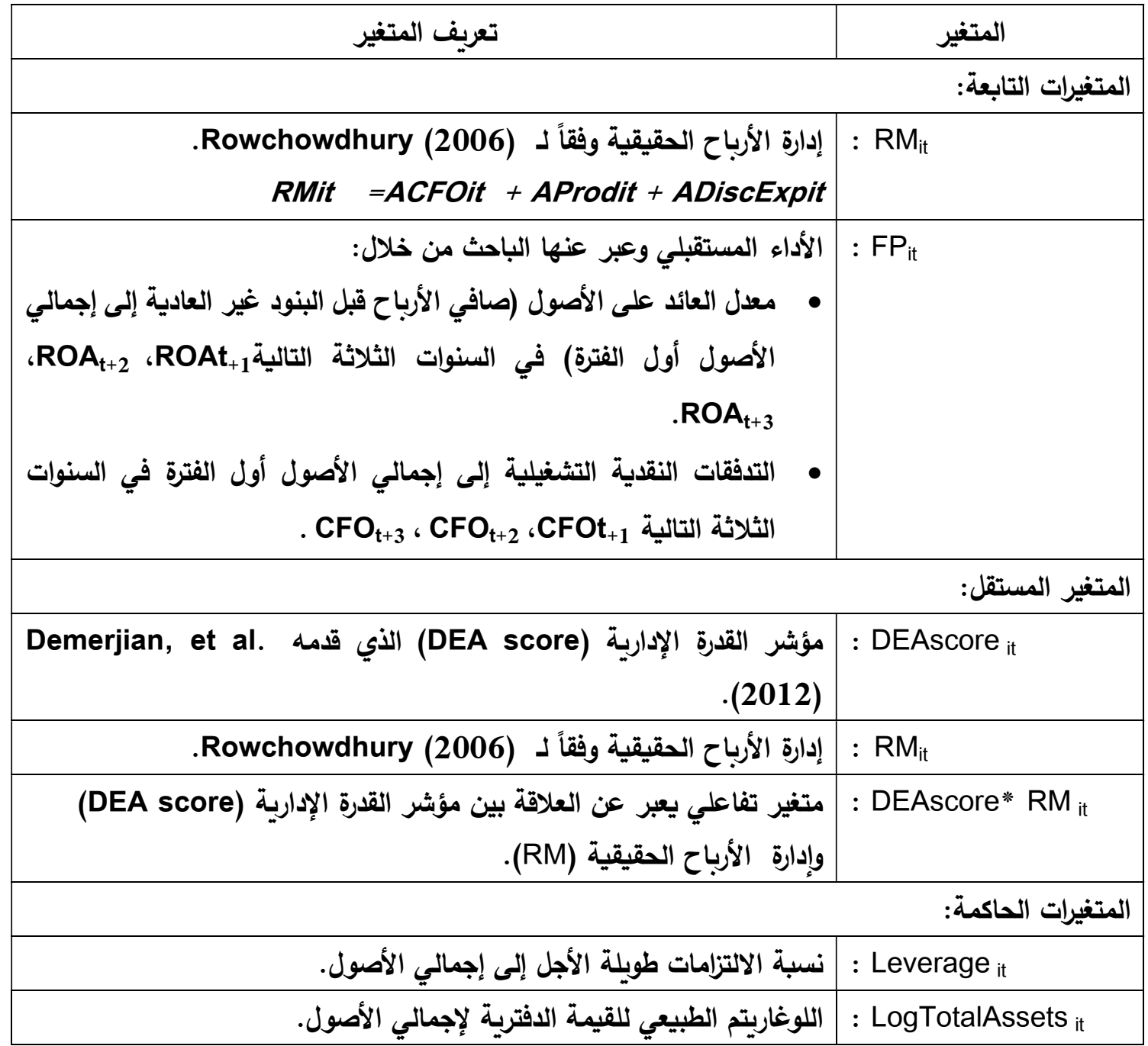

رابعاً عينة البحث والإحصائيات الوصفية:

اشتملت الاراسة التطبيقية على عينة مكونة من 55" شركة من الثركات غير المالية المقيدة بسوق

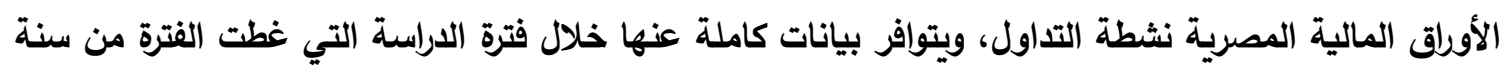
* العينة الحالية استبعد منها الشركات ذات القيم الدنطرفة Outliers خلال فترة الدراسة وذلك لضمان صلاحية النتائج. 
2005 إلى سنة 2015، وقد تضمنت العينة 5 شركات مقيدة أسهمها في بورصة لندن بنسبة 9\% تقريبًا من إجمالي حجم العينة، أما عن توزيع عينة الدراسة حسب القانون الخاضعة له الثركات الممثلة في عينة الدراسة، فاشتملت

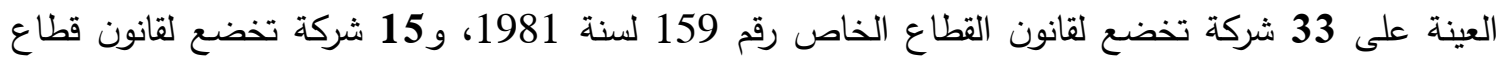
الأعمال العام رقم 203 لسنة 1991، و8 شركات تخضع لقانون الاستثمار رقم 8 لسنة 1997. وتتوزع العينة على ونى 6 قطاعات اقتصادية موضحة بالجدول التالي.

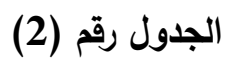

التوزيع القطاعي لعينة الدراسة التطبيقية

\begin{tabular}{|c|c|c|}
\hline النسبة من العينة & عدد الثركات & \\
\hline$\% 25$ & 14 & الموارد الأساسية والتشييد ومواد البناء \\
\hline$\% 24$ & 13 & الأغذية والمشروبات \\
\hline$\% 13$ & 7 & الكيماويات \\
\hline$\% 13$ & 7 & المنتجات المنزلية والثخصية \\
\hline$\% 15$ & 8 & الاتصالات والخدمات والمنتجات الصناعية \\
\hline$\% 11$ & 6 & العقارات \\
\hline$\% 100$ & 55 & إجمالي حجم العينة \\
\hline
\end{tabular}

وتتضي طبيعة فروض ومتغيرات الدراسة توفير القوائم المالية المجمعة السنوية للشركات خلال الفترة من

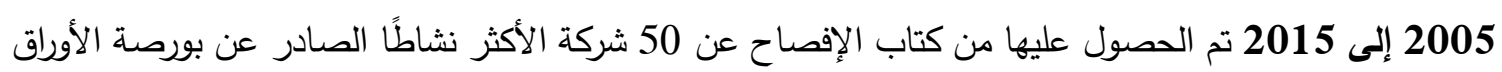

المالية المصرية ودليل كومباس مصر KOMPASS الصادر عن شركة

(3 ) i G̦

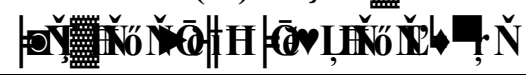

\begin{tabular}{|l|c|c|c|c|}
\hline & Minimum & Maximum & Mean & Std. Deviation \\
\hline RM & .0310 & 4.9517 & .696 & .6954 \\
\hline DEAscore & -.9031 & .4820 & -.000096 & .1740 \\
\hline DEAscore $^{*} \mathbf{R M}$ & -1.06 & .89 & .0066 & .178 \\
\hline ROI $_{+1}$ & $-12.01 \%$ & $18.34 \%$ & $6.2872 \%$ & $5.56726 \%$ \\
\hline ROI $_{+2}$ & $-10.01 \%$ & $19.65 \%$ & $6.3058 \%$ & $5.20313 \%$ \\
\hline ROI $_{+3}$ & $-8.01 \%$ & $16.25 \%$ & $5.5325 \%$ & $5.05871 \%$ \\
\hline CFO $_{+1}$ & -.1579 & .2741 & .054084 & .0695971 \\
\hline CFO $_{+2}$ & -.1513 & .1669 & .051514 & .0549 \\
\hline CFO $_{+3}$ & -.15 & .23 & .0454 & .05344 \\
\hline Leverage & 0 & .752 & .1393 & .1576 \\
\hline LogTotalAssets & 4 & 8 & 5.83 & .739 \\
\hline
\end{tabular}


تستخدم الإحصاءات الوصفية لوصف الملامح الأساسية لبيانات الدراسة، كما تفيد في استكثاف طبيعة

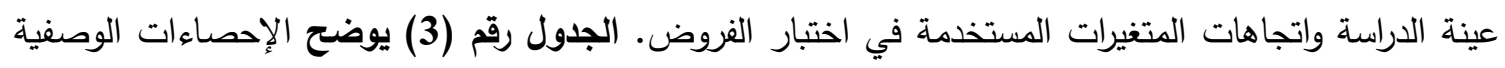

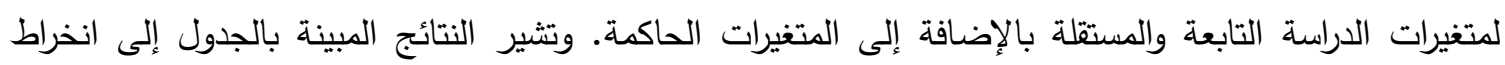

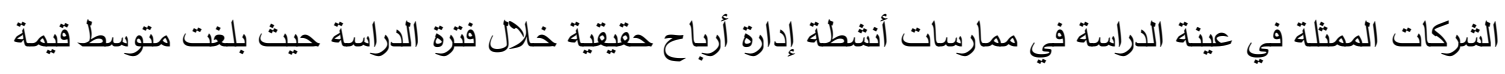

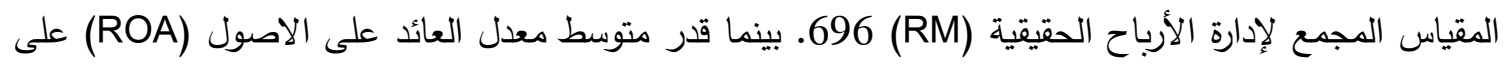
في السنوات الثلاثة التالية لكل سنة على مستوى كل شركة 6.04\% وفي حين أن متوسط التدفقات النقدية التشغيلية إلى إجمالي الأصول (CFO) 8.8 \% للسنوات الثلاثة التالية لكل سنة على مستوى كل شركة. كما تثير الإحصاء ات

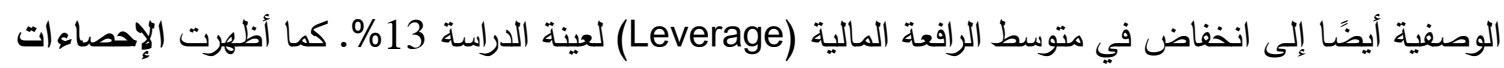
الوصفية أن مؤشر القدرة الإدارية (DEA score) لعينة الدراسة أقترب من الصفر واتسم بإثارة سالبة حيث بلغت

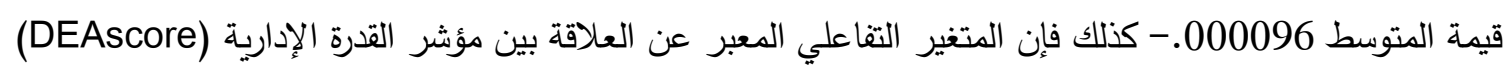

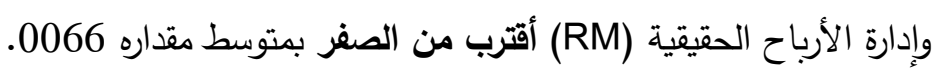



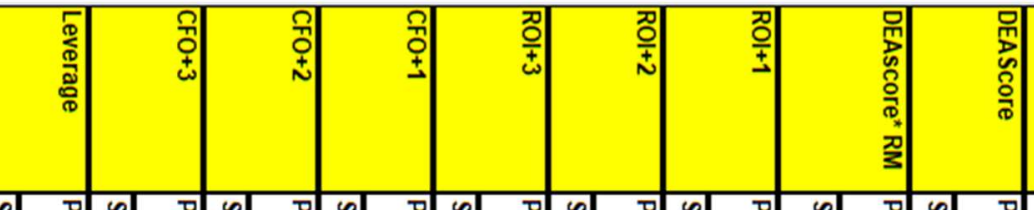

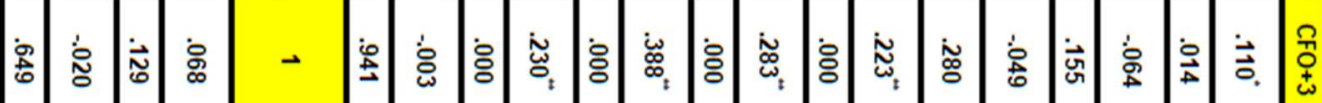

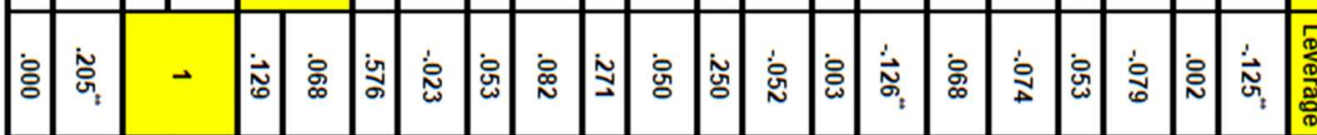


الجدول رقم (4) يوضح مصفوفة الارتباط لمعاملات الارتباط الخطي Pearson لمتغيرات الدراسة عند مستوى معنوية 5\% و 1\%. فكما يوضح الجدول رقم (4) احتمالية وجود علاقة ارتباط سالبة معنوية بين إدارة الأرباح الحقيقية (RM) ومعدل العائد على الأصول (ROA) في السنتين الأولى والثانية فقط (ROA (ROA )

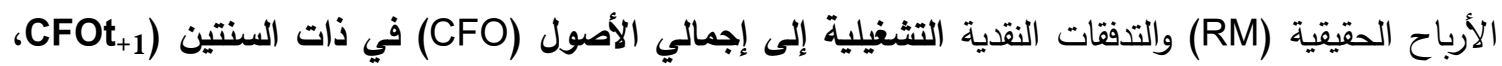
.(CFO $\mathrm{CH}_{\mathrm{t}+2}$

كما أظهرت معاملات الارتباط الخطي الموضحة بالجدول رقم (4) احتمالية عدم وجود ارتباط بين المتغير

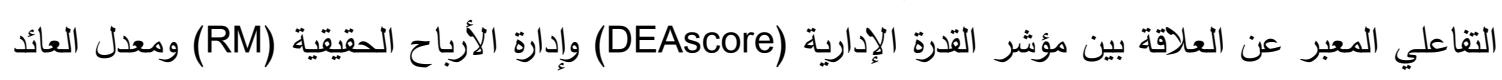
على الأصول (ROA) والتدفقات النقدية التشغيلية إلى إجمالي الأصول (CFO) للسنوات الثلاثة التالية لكل سنة.

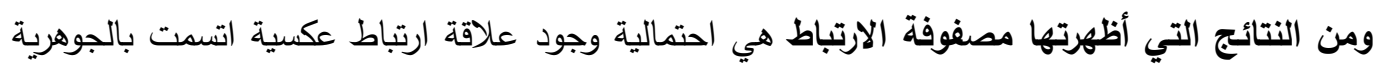
بين إدارة الأرباح الحقيقية (RM) وكلاً من الرافعة المالية للشركة (Leverage) وحجم الثركة (LogTotalAssets).

خامساً نتائج الاراسة التطبيقية: استخدم الباحث الإحصاءات الوصفية ومصفوفة الارتباط بهدف استكثاف طبيعة متغيرات الدراسة والعلاقات بين المتغيرات في عينة الدراسة، ولكن في هذه المرحلة من الدراسة حاول الباحث من خلال تطبيق الأساليب الإحصائية

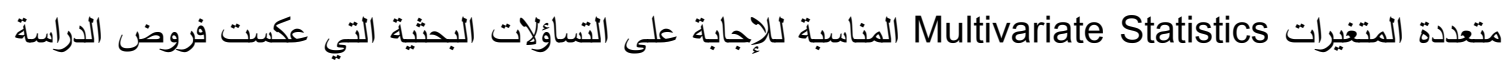
السابق عرضها، ولكن قبل عرض نماذج الدراسة وللتأكد من صلاحية النماذج فقد تم اختبار مدى خلو النموذج من مشكلة الازدواج الخطي Multicollinearity بين المتغيرات المستقلة و الحاكمة، وقد تبين من واقع نتائج اختبار (VIF) على النحو الموضح بالجدول رقم (5) أن المتغيرات لا تعاني من مشكلة الازدواج

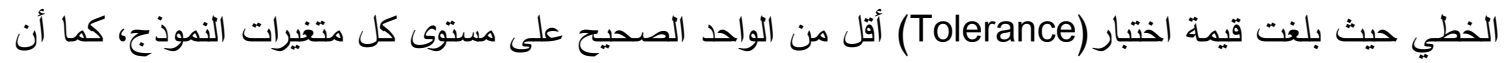
قيمة اختبار (VIF) أقل من (10) على مستوى كل متغيرات النموذج ومن ثم نقبل فرض العدم بعدم وجود ازدواج خطي بين المتغيرات المستقلة و الحاكمة.

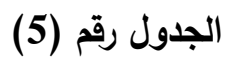

نتائج اختبار مشكلة الازدواج الخطي بين متغيرات الاراسة المستقلة والحاكمة

\begin{tabular}{|l|c|c|}
\hline \multirow{2}{*}{\multicolumn{1}{|c|}{}} & \multicolumn{2}{c|}{ Collinearity Statistics } \\
\cline { 2 - 3 } & Tolerance & VIF \\
\hline RM & .871 & 1.148 \\
\hline DEAscore & .423 & 2.364 \\
\hline Leverage & .937 & 1.067 \\
\hline LogTotalAssets & .845 & 1.184 \\
\hline DEA score *RM & .423 & 2.365 \\
\hline
\end{tabular}


أحد الفرضيات الأساسية في تحليل الانحدار هي ثبات تباين الأخطاء العشوائية Homoscedasticity،

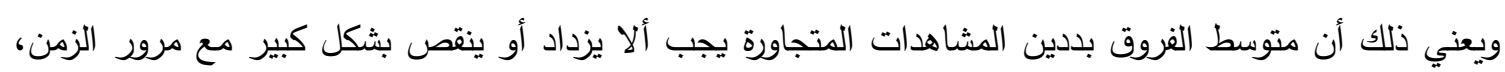

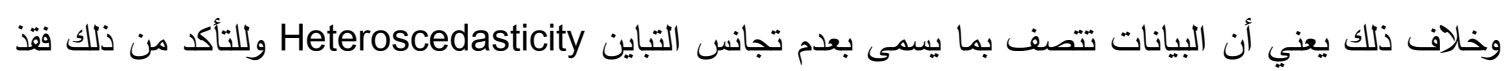

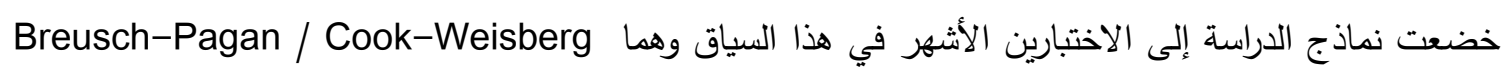
White's General Test و والتي أكدت عدم ثبات تباين الأخطاء العثوائية أو عدم تجانس التباين حيث

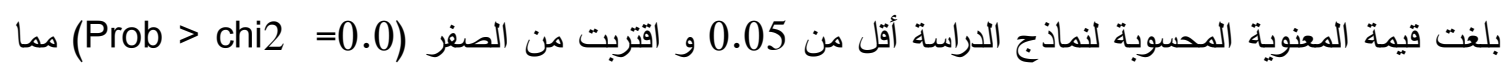
يثبت صحة الفرضية الأساسية للاختبار عدم ثبات تباين الأخطاء العشوائية وللتغلب على تلك المشكلة بمعالجة تباين الأخطاء من خلال استخدام خاصية Robust Standard Errors المتاحة بالحزمة الإحصائية Stata

أخيراً، فإن طبيعة التحليل القطاعي الزمني Panel Data يقتضى الاختيار بين أحدى طريقتين لتشغيل نماذج الدراسة هما طريقة نماذج التأثيرات الثابتة Fixed Effects (LSDV) وطريقة التأثيرات العشوائية Random Effects، وبشكل عام نظراً لان عدد بيانات السلسلة الزمنية (11 سنة) أقل من عدد الوحدات القطعية (55 شركة) والمسحوبة كعينة عشوائية من مجتمع أكبر (213 شركة) يكون من الأفضل استخدام طريقة التأثيرات

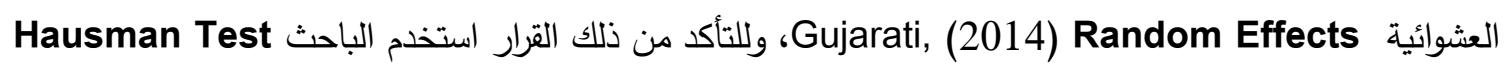

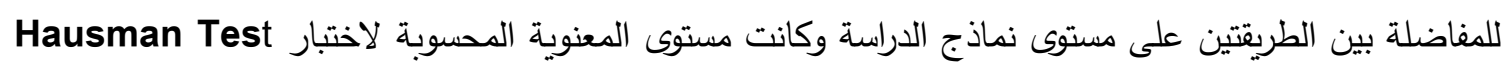
لنماذج الدراسة أكبر من 5andom ما يثرائ صحة الفرض البديل بصلاحية طريقة التأثيرات العشوائية . Effects

وقد استهدف النموذج الأول اختبار العلاقة بين القدرة الإدارية للمديرين والأنثطة الحقيقية لإدارة الأرباح (التلاعب

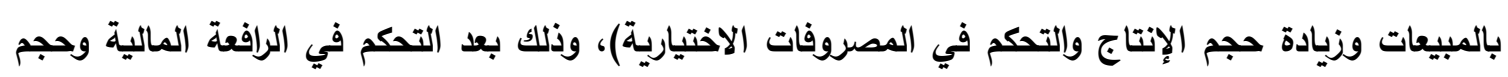

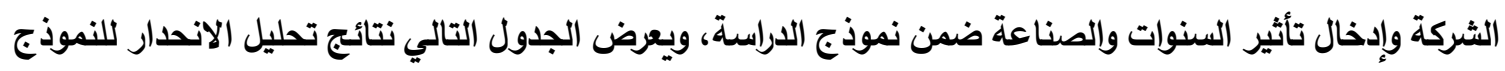
الأول: - التركه

$$
\text { (6) الجدول رقم (6) }
$$

نتائج تحليل الانحدار للنموذج الأول

تأثير القدرة الإدارية للمديرين على الأنثطة الحقيقية لإدارة الأرباح

\begin{tabular}{|c|c|c|c|}
\hline $\begin{array}{l}\mathrm{RM}_{\mathrm{it}}=\beta_{0}+\beta_{1} \text { DEA sco } \\
\varepsilon \\
\text { Random-effects GLS } \mathrm{r}\end{array}$ & $\begin{array}{l}\text { it }+\beta_{2} \text { Lel } \\
\text { ression } n\end{array}$ & $\begin{array}{l}\text { erage } \\
\text { ith 'ro }\end{array}$ & $\begin{array}{l}\text { sets } \\
\text { it } \\
\text { for heter }\end{array}$ \\
\hline Dependent Var. = $\mathbf{R M}_{\mathbf{i t}}$ & Coef. & $\mathrm{z}$. & $P>|z|$ \\
\hline Constant & 2.3318 & 9.51 & 0.000 \\
\hline DEA score & .2124 & 2.70 & 0.007 \\
\hline Leverage & .17146 & 1.23 & 0.217 \\
\hline LogTotalAssets & -.2601 & $\begin{array}{c}- \\
5.98\end{array}$ & 0.000 \\
\hline Year & Includec & & \\
\hline
\end{tabular}




\begin{tabular}{|l|l|}
\hline Industry & Included \\
\hline Wald Test & $735.37 \quad$ Prob $>$ chi2 = 0.0000 \\
\hline R-square: & 0.3357 \\
\hline Number of obs. & 605 \\
\hline
\end{tabular}

وقد أثارت نتائج تحليل الانحدار المتعدد بالجدول رقم (4) إلى وجود علاقة إيجابية بين القدرة الإدارية

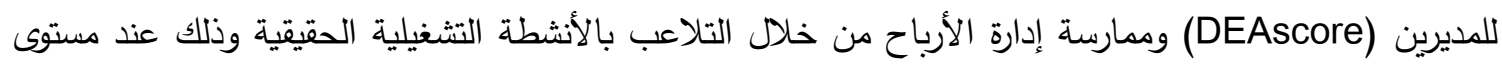
معنوية 0.01. وهي النتيجة التي تقترح استثمار المديرين لقدراتهم ومهاراتهم في التلاعب بالأرباح من خلال ممارسة أنثطة إدارة الأرباح الحقيقة بزيادة حجم المبيعات بثكل وهمى، تحقيق مستويات غير عادية من الإنتاج، والتحكم في النفقات الاختيارية بهدف توجيه الأرباح لمستويات معينه مستهدفه سلفاً وذلك كبديل عن استخدام الإدارة لمهاراتهم

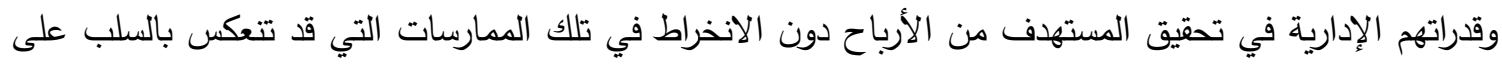
الأداء المستقبلي و هي النتيجة التي جاءت مناقضة لنتيجة لاراسة (2017 (Huang \& Sun بوجود علاقة عكسية بين القدرة الإدارية للمديرين وإدارة الأرباح الحقيقية، فالإدارة إذا كانت بتتسم بقدرات إدارية مرتفعة تستخدم الموارد

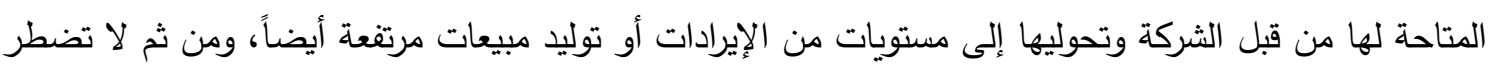

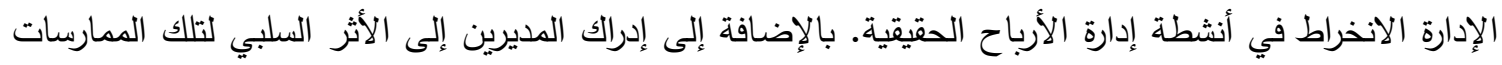

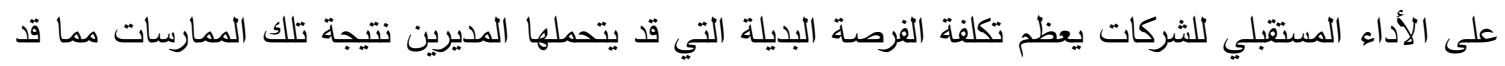

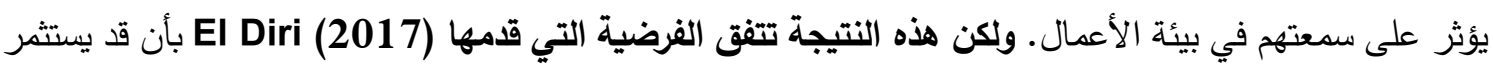

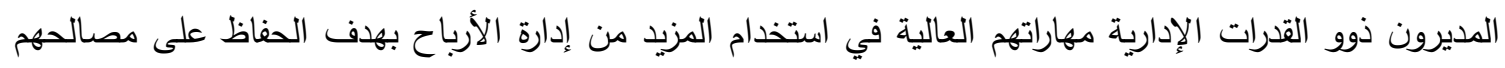

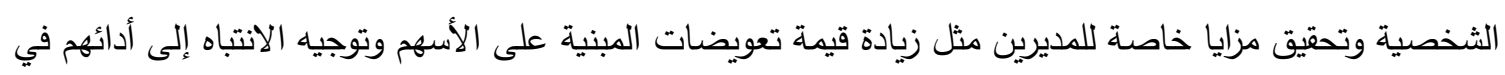

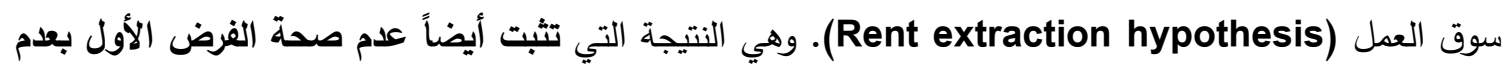
وجود تأثير للقدرة الإدارية للمديرين على الإدارة الحقيقية للأرباح.

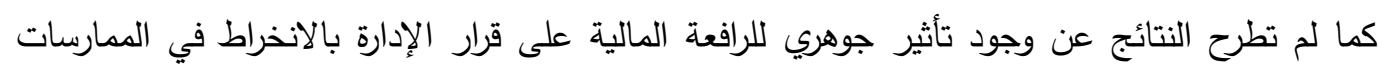
الاحتيالية من خلال التلاعب بالأنشطة التشغيلية الحقيقية. أما عن حجم الثركة فقد أوضحت التهاتير النتائج وجود تأثير

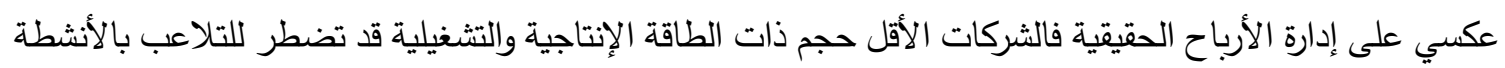

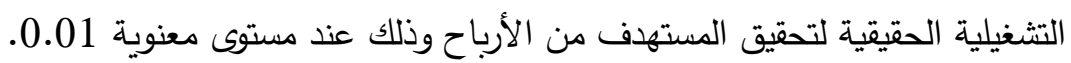
وفي ذات السياق، استهدف النموذج الثاني اختبار تأثير القدرة الإدارية للمديرين على العلاقة بين الأنشطة الحقيقية

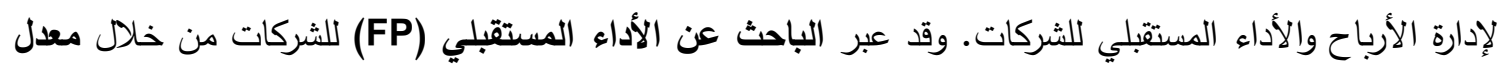

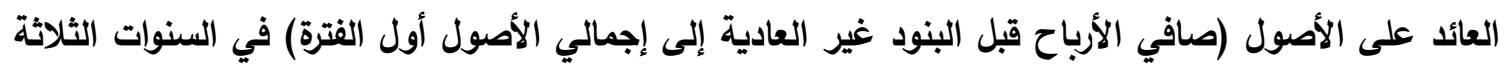

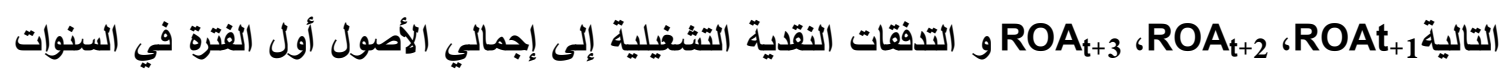
الثلاثة التالية

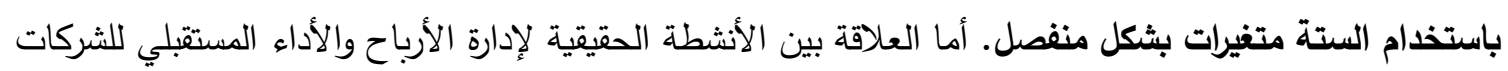
فقد عبر عنها الباحث من خلا متغير تفاعلي (DEAscore* RM) يعبر عن العلاقة بين مؤشر القدرة الإدارية (DEA score)

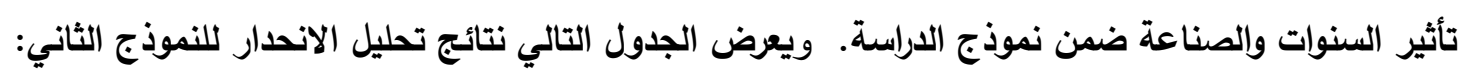




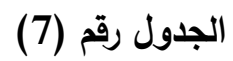

$$
\text { نتائج تحليل الانحدار للنموذج الثاني }
$$

تأثير القدرة الإدارية للمديرين على العلاقة بين الأنشطة الحقيقية لإدارة الأرباح والأداء المستقبلي للشركات $\mathrm{FP}_{\mathrm{it}}=\beta_{0}+\beta_{1}$ DEAscore $_{\text {it }}+\beta_{2} \mathrm{RM}_{\mathrm{it}}+\beta_{3}$ DEAscore* RM $_{\text {it }}+\beta_{4}$ Leverage $_{\text {it }}+$ $\beta_{5}$ LogTotalAssets $_{\text {it }}+$ Year +Industry $+\varepsilon$

Random-effects GLS regression with 'robust' to control for

\begin{tabular}{|c|c|c|c|c|c|c|}
\hline & Model 2-1 & Model 2-2 & Model 2-3 & Model 2-4 & Model 2-5 & Model 2-6 \\
\hline Dependent var. & $\mathrm{ROAt}_{+1}$ & $\mathrm{ROAt}_{+2}$ & $\mathrm{ROAt}_{+3}$ & $\mathrm{CFOt}_{+1}$ & $\mathrm{CFOt}_{+2}$ & $\mathrm{CFOt}_{+3}$ \\
\hline \multicolumn{7}{|l|}{ Independt Vars. } \\
\hline \multirow{2}{*}{ Constant } & 0.0010 & $(0.0009)$ & 0.0065 & $(0.0265)$ & $(0.0306)$ & 0.0148 \\
\hline & 0.973 & 0.9770 & 0.8460 & 0.5380 & 0.4500 & 0.6640 \\
\hline \multirow{2}{*}{ RM } & $(0.0254)$ & $(0.0197)$ & 0.0035 & $(0.0164)$ & $(0.0095)$ & $(0.0075)$ \\
\hline & 0.0000 & 0.0020 & 0.3770 & 0.0 .39 & 0.092 & 0.099 \\
\hline \multirow{2}{*}{ DEAscore } & 0.006539 & $(0.0142)$ & $0.0353-$ & 0.06638 & 0.0154 & 0.0151 \\
\hline & 0.8280 & 0.5810 & 0.1980 & 0.003 & 0.4550 & 0.7660 \\
\hline \multirow{2}{*}{ DEAscore*RM } & 0.0012 & 0.0179 & 0.0301 & $(0.0504)$ & $(0.0070)$ & 0.0092 \\
\hline & 0.9700 & 0.4790 & 0.1820 & 0.168 & 0.7520 & 0.7860 \\
\hline \multirow{2}{*}{ Leverage } & $(0.0349)$ & $(0.0071)$ & 0.0186 & 0.01685 & 0.0119 & 0.0385 \\
\hline & 0.0830 & 0.7100 & 0.1750 & 0.422 & 0.7220 & 0.2200 \\
\hline \multirow{2}{*}{ LogTotalAssets } & 0.0107 & 0.0117 & 0.0103 & 0.0135 & 0.0153 & 0.0067 \\
\hline & 0.0210 & 0.0190 & 0.1110 & 0.065 & 0.02 & 0.2380 \\
\hline Year & Included & Included & Included & Included & Included & Included \\
\hline Industry & Included & Included & Included & Included & Included & Included \\
\hline Wald Test & 42.36 & 25.15 & 8.8 & 36.19 & 30.12 & 9.52 \\
\hline Prob > chi2 & 0.0000 & 0.0010 & 0.1171 & 0.0000 & 0.0000 & 0.0899 \\
\hline Number of obs. & 549 & 495 & 441 & 549 & 495 & 441 \\
\hline
\end{tabular}
heteroskedasticity.

$\mathrm{FP}_{\mathrm{it}}=$

$$
\begin{aligned}
& \mathrm{ROI}_{+1} \\
& \mathrm{ROI}_{+2} \\
& \mathrm{ROI}_{+3} \\
& \mathrm{CFO}_{+1} \\
& \mathrm{CFO}_{+2} \\
& \mathrm{CFO}_{+3}
\end{aligned}
$$

أوضحت نتائج تحليل الانحار المتعدد بالجدول رقم (5) عن وجود تأثير سلبي جوهري لتدخل الإدارة في

الأرباح من خلال التحكم في أنشطة التشغيل الحقيقية على الأداء المستقبلي للشركات المعبر عنها سواء من خلادل معدل العائد على الأصول خلال السنتين التاليتين أو بالتدفقات النقدية التشغيلية إلى إجمالي الأصول خلال الثلاثة 
سنوات التالية وهي النتيجة التي تتفق مع دراسة (2017) Huang \& Sun ودراسة (2005) Gunny. ولكن هل يمكن للقدرة الإدارية للمديرين أن تخفف من الأثر السلبي لأنثطة إدارة الأرباح الحقيقية على الأداء المستقبلي ولثي

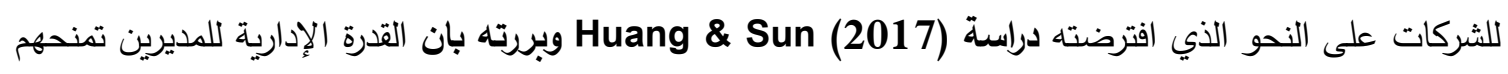
فهم أفضل للشركات التي يقومون بإداراتها وبيئة عمل شركاتهم، فيمكن للمديرين ذوي القدرة العالية على مواءمة

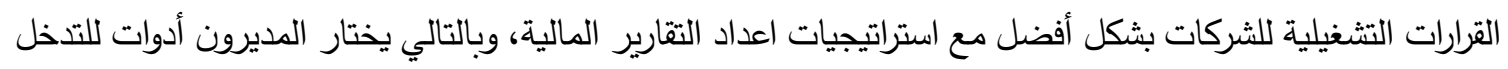

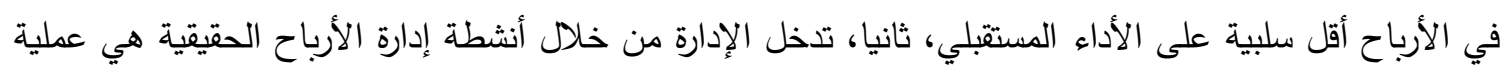

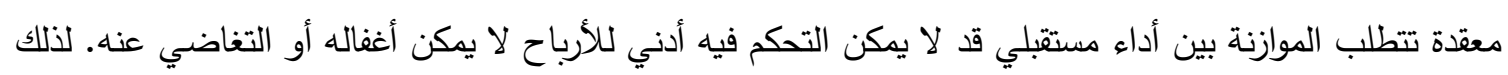
فإن المديرين من ذوي القدرات الإدارية المشهود لها من المتوقع أن تكون قادرة على تقدير الأرباح المستقبلية وتحديد

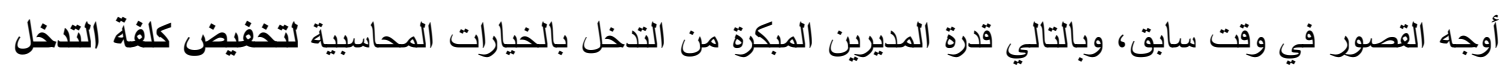

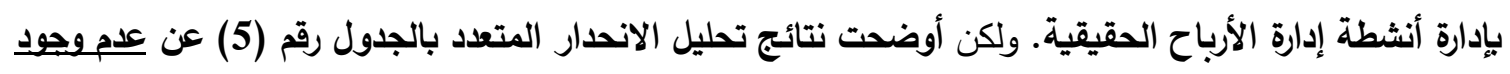
تأثير جوهري للمتغير التفاعلي (DEAscore* RM) الذي استخدمه الباحث لاستكشاف تأثير للقدرة الإدارية

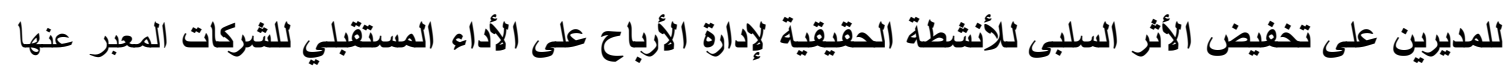

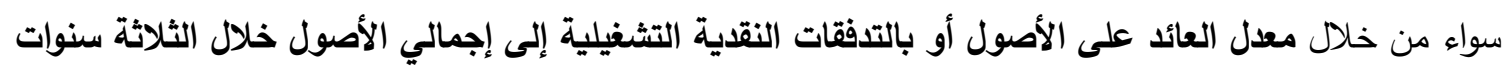

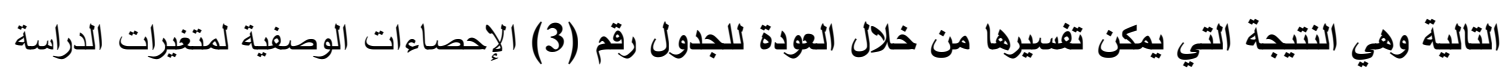
واستدراك متوسط مؤشر القدرة الإدارية (DEA score) لعينة الدراسة والذي اقترب من الصفر واتسم بإشارة سالبة حيث بلغت قيمة المتوسط (000096.-) مما قد يعكس محدودية القدرة الإدارية للمدرين للعينة الممثلة في الدراسة

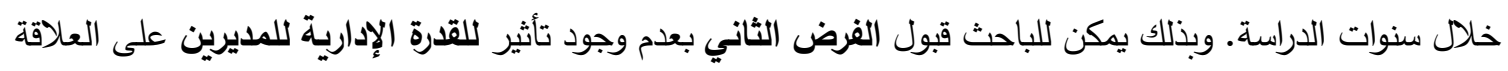

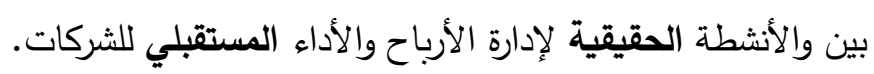

سادساً الخلاصة:

متع الشركات بمديرين تتفيذين على رأس إداراتها من ذوي الخبرة والسمعة الطيبة يمنحهم القدرة على صناعة

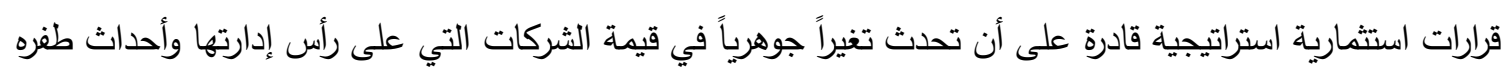

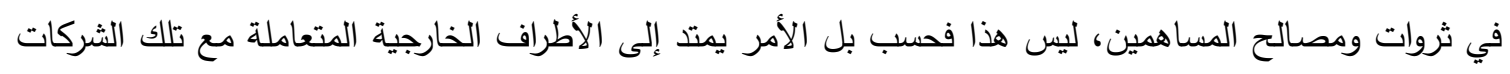

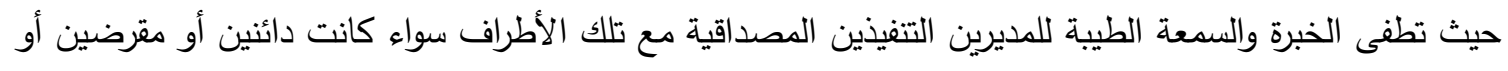

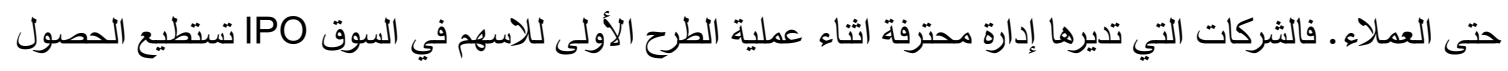

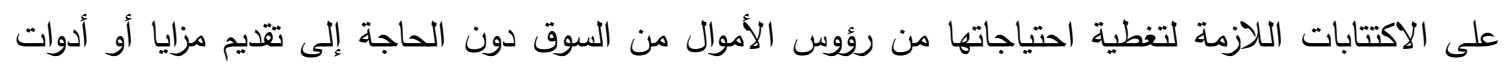

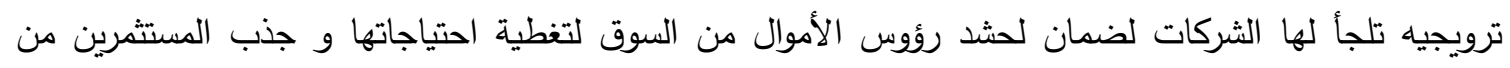
المؤسسات بحيازات كبيرة والتي ممكن أن تحمل في طياها تأثيرا إيجابيا على كفاءة الاستثمارات من خلال دوف دورها الرقابي، بالإضافة إلى أن هذه الثركات تكون قادة على أحداث طفره في أداء الثركات في السنوات اللاحقة لزيادة راس المال.

استهدف البحث الحالي دراسة دور القدرة الإدارية للمديرين التنفيذين في تخفيض الأثر السلبي لأنشطة

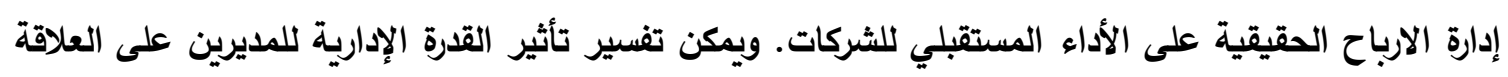

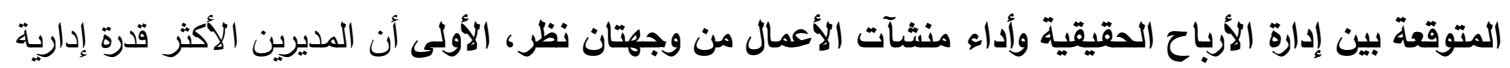

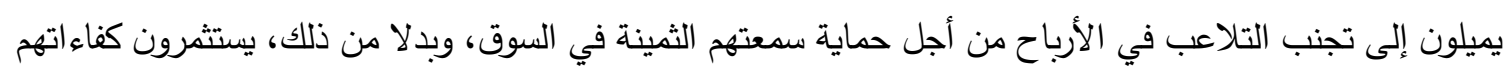

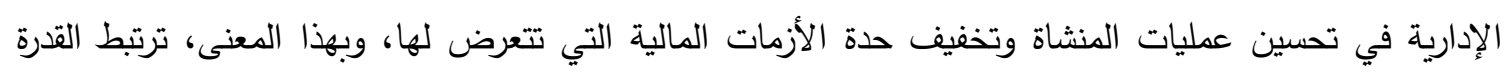


الإدارية الأفضل بجودة عالية من الأرباح للسماح للمديرين بالحفاظ على خطط المستتدة إلى السمعة ؛ ويمكن تحديد

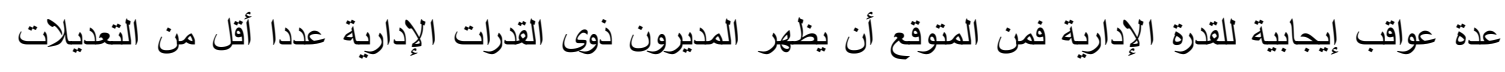

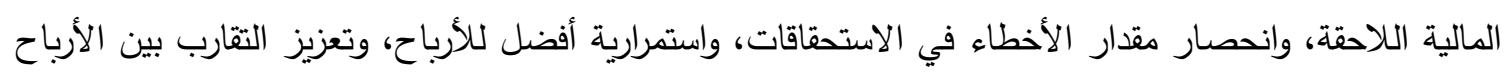
والتدفقات النقدية التثغيلية. وقد يصبح دورهم أكثر وضوحا في المستقبل نظرا لارتباطهم عموما بتحسين أداء الأعمال

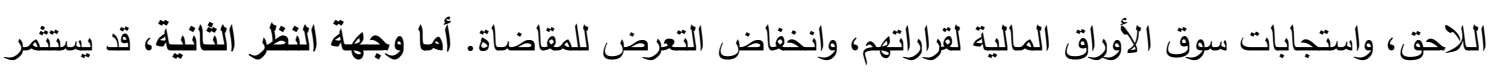

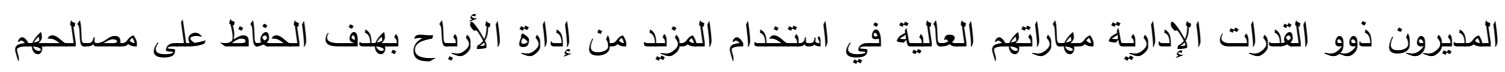

الثخصية وتحقيق مزايا خاصة للمديرين مثل زيادة قيمة التعويضات المبنية على الأسهم وتوجيه الانتباه إلى أدائهم في سوق العمل.

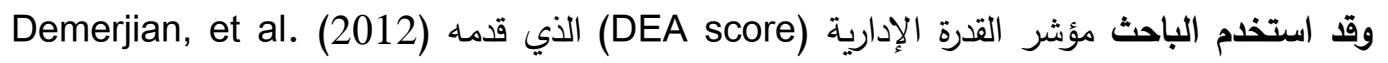
لقياس القدرة الإدارية للمديرين بناء على كفاء استغلال المديرين للموارد المتاحة وتحقق أعلى مقدار من المخرجات

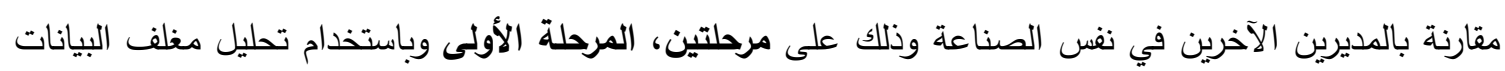
Data Envelopment Analysis (DEA)

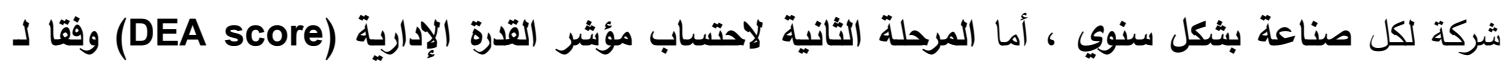
(استبعاد تأثير بعض الخصائص الثركة المؤثرة على درجة الكفاءة الكلية وتحديد مؤشر القدرة الإدارية بيواقي Residual علاقة الانحدار Tobit Regression تتسب إلى القدرة الإدارة للمديرين

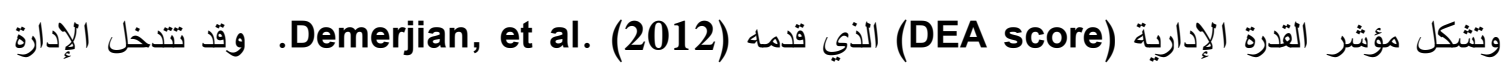
بالتحكم في التقارير المالية ولاسيما في نتائج الأعمال من خلال التحكم في توقيت أو هيكلة مجموعة من القرارات

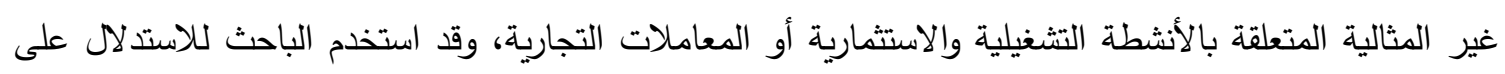

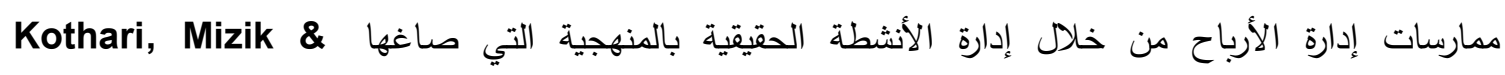
Roychowdhury (2016) و و Rowchowdhury (2006) وقد عبر الباحث عن الأداء المستقبلي من خلال معدل العائد على الأصول (ROA) والتدفقات النقدية التثغيلية إلى إجمالي الأصول (ROA) و (CFO) للثلاثة سنوات التالية لكل سنة (Gunny 2010 ; Huang \& Sun 2017 وقد تمت الدراسة من خلال تحليل قطاعي زمني الاصول يغطى السنوات من 2005 إلى 2015 لـ 55 شركة. وقد خلصت نتائج الدراسة إلى وجود علاقة تصنة إيجابية وجوهرية بين القدرة الإدارية للمديرين وممارسة إدارة الأرباح من خلال التلاعب بالأنشطة التشغيلية الحقيقية. وهي النتيجة التي تقترح استثمار المديرين لقدراتهم ومهاراتهم في التلاعب بالأرباح من خلال ممارسة أنثطة إدارة الأرباح الحقيقة بزيادة حجم المبيعات بشكل وهمي، تحقيق مستويات غير عادية من الإنتاج، والتحكم في النفقات الاختيارية بهدف توجيه الأرباح لمستويات معينه مستهدفه سلفاً وذلك كبديل عن استخدام الإدارة لمهاراتهم وقدراتهم الإدارية في تحقيق المستهدف من الأرباح دون الانخراط في تلك الممارسات التي انعكست بالسلب علب على الأداء

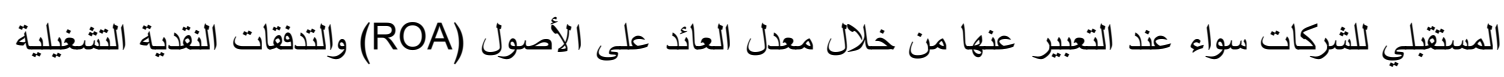

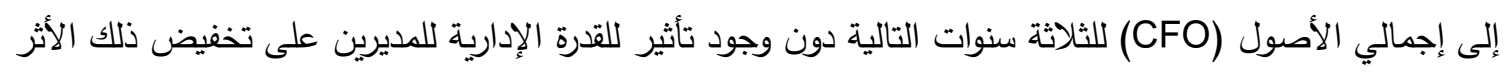
السلبى للأنشطة الحقيقية لإدارة الأرباح على الأداء المستقبلي للشركات. 


\section{References}

Abernathy, J. L., Beyer, B., \& Rapley, E. T. (2014). Earnings management constraints and classification shifting. Journal of Business, Finance and Accounting, 41(5), 600-629. https://doi.org/10.1111/jbfa.12076

Aier, J. K., Comprix, J., Gunlock, M. T., \& Lee, D. (2005). The financial expertise of CFOs and accounting restatements. Accounting Horizons, 19(3), 123-135. https://doi.org/10.2308/acch.2005.19.3.123

Alareeni, B. A., \& Branson, J. (2013). Predicting listed companies' failure in Jordan using Altman models: A case study. International Journal of Business and Management, 8(1), 113-126. https://doi.org/10.5539/ijbm.v8n1p113

Alareeni, B. and Aljuaidi, O. (2014). The Modified Jones and Yoon Models in detecting earnings management in Palestine Exchange (PEX). International Journal of Innovation and Applied Studies, 9(4), 2028-9324.

Alareeni, B. and Branson, J. (2011). The relative performance of auditors' going-concern opinions and statistical failure prediction models in Jordan. Accountancy \& Bedrijfskunde, 8, 23-35.

Andreou, P. C., Louca, C., \& Petrou, A. P. (2017). CEO age and stock price crash risk. Review of Finance, 21(3), 1287-1325. https://doi.org/10.1093/rof/rfw056

Athanasakou, V., Strong, N. C., \& Walker, M. (2009). Earnings management or forecast guidance to meet analyst expectations?. Accounting and Business Research, 39, 335. https://doi.org/10.1080/00014788.2009.9663347

Baik, B. O. K., Farber, D. B., \& Lee, S. S. (2011). CEO ability and management earnings forecasts. Contemporary Accounting Research, 28(5), 1645-1668. https://doi.org/10.1111/j.1911-3846.2011.01091.x

Baik, B., Brockman, P. A., Farber, D. B., \& Lee, S. (2017). Managerial ability and the quality of firms' information environment. Journal of Accounting, Auditing \& Finance. In Press. https://doi.org/10.1177/0148558X17742820

Baker, M., Litov, L., Wachter, J., \& Wurgler, J. (2005). Can mutual fund managers pick stocks? Evidence from their trades prior to earnings announcements. Working PaperNew York University. https://doi.org/10.2139/ssrn.570381

Bamber, L. S., Jiang, J., \& Wang, I. Y. (2010). What's my style? The influence of top managers on voluntary corporate financial disclosure. The Accounting Review, 85(4), 1131-1162. https://doi.org/10.2308/accr.2010.85.4.1131

Barton, J. (2001). Does the use of financial derivatives affect earnings management decisions?. The Accounting Review, 76, 1-26. https://doi.org/10.2308/accr.2001.76.1.1

Barton, J., \& Simko, P. (2002). The balance sheet as an earnings management constraint. The Accounting Review, 77, 1-27. https://doi.org/10.2308/accr.2002.77.s-1.1

Bertrand, M., \& Schoar, A. (2003). Managing with style: The effect of managers on firm policies. The Quarterly Journal of Economics, 118(4), 1169-1208. https://doi.org/10.1162/003355303322552775

Bhojraj, S., Hribar, P., Picconi, M., \& McInnis, J. (2009). Making sense of cents: An examination of firms that marginally miss or beat analyst forecasts. The Journal of Finance, 64(5), 2361-2388. https://doi.org/10.1111/j.1540-6261.2009.01503.x

Bonsall, S. B., IV, Holzman, E. R., \& Miller, B. P. (2017). Managerial ability and credit risk assessment. Management Science. 63(5), 1425-1449. https://doi.org/10.1287/mnsc.2015.2403 
Brown, K., Chen, V., \& Kim, M. (2015). Earnings management through real activities choices of firms near the investment - Speculative grade borderline. Journal of $\begin{array}{lllll}\text { Accounting } \quad \text { Public } & \text { Policy, 34-94. }\end{array}$ https://doi.org/10.1016/j.jaccpubpol.2014.09.002

Chemmanur, J. T., \& Paeglis, I. (2005). Management quality, certification, and initial public offerings. Journal of Financial Economics, 76(2), 331-368. https://doi.org/10.1016/i.jfineco.2004.10.001

Chemmanur, J. T., Paeglis, I., \& Simonyan, K. (2009). Management quality financial investments and asymmetric information. Journal of Financial and Quantitative Analysis, 44(5), 1045-1079. https://doi.org/10.1017/S0022109009990299

Chemmanur, J. T., Paeglis, I., \& Simonyan, K. (2010). Management quality and equity issue characteristics: A comparison of SEOs and IPOs. Financial Management, 39(4), 1601-1642. https://doi.org/10.1111/j.1755-053X.2010.01124.x

Chemmanur, T. J. and I. Paeglis (2005). Management quality, certification, and initial public offerings. Journal of Financial Economics, 76, 331-368. https://doi.org/10.1016/j.jfineco.2004.10.001

Chemmanur, T. J., Paeglis, I., \& Simonyan, K. (2009). Management quality, financial and investment policies, and asymmetric information. Journal of Financial \& Quantitative Analysis, 44, 1045-1079. https://doi.org/10.1017/S0022109009990299

Choi, W., Han, S., Jung, S. H., \& Kang, T. (2015). CEO's operating ability and the association between accruals and future cash flows. Journal of Business Finance \& Accounting, 42(5-6), 619-634. https://doi.org/10.1111/jbfa.12118

Cohen, D. A., \& Zarowin, P. (2010). Accrual-based and real earnings management activities around seasoned equity offerings. Journal of Accounting and Economics, 50, 2-19. https://doi.org/10.1016/i.jacceco.2010.01.002

Cohen, D. A., Dey, A., Mashruwala, R., \& Zach, T. (2010). The use of advertising activities to meet earnings benchmarks: Evidence from monthly data. Review of Accounting Studies, 15, 808-832. https://doi.org/10.1007/s11142-009-9105-8

Cohen, D., Dey, A., \& Lys, T. (2008). Real and accrual-based earnings management in the pre- and post-Sarbanes-Oxley periods. The Accounting Review, 83(3), 757-787. https://doi.org/10.2308/accr.2008.83.3.757

Cornaggia, K., Krishnan, G., \& Wang, C. (2016). Managerial ability and credit ratings. Working paper available at SSRN. https://ssrn.com/abstract=2541699.

Demerjian, P. R., Lewis, M. F., \& Mcvay, S. E. (2013b). Managerial ability and earnings management. Working paper, Emory University. https://doi.org/10.2139/ssrn.1650309

Demerjian, P. R., Lewis-Western, M. F., \& McVay, S. (2017). How does intentional earnings smoothing vary with managerial ability? .Working paper. https://doi.org/10.1177/0148558X17748405

Demerjian, P., Lev, B., \& McVay, S. (2012). Quantifying managerial ability: A new measure and validity tests. Management Science, 58(7), 1229-1248. https://doi.org/10.1287/mnsc. 1110.1487

Demerjian, P., Lewis, M., Lev, B., \& McVay, S. (2013a). Managerial ability and earnings quality. The Accounting Review, 88(2), 463-498. https://doi.org/10.2308/accr-50318

Dyreng, S. D., Hanlon, M., \& Maydew, E. L. (2010). The effects of executives on corporate tax avoidance. The Accounting Review, 85(4), 1163-1189. https://doi.org/10.2308/accr.2010.85.4.1163

El Diri, M. (2017). Introduction to Earnings Management. Springer. https://doi.org/10.1007/978-3-319-62686-4 
Eldenburg, L., Gunny, K., Hee, K., \& Soderstrom, N. (2011). Earnings management using real activities: Evidence from nonprofit hospitals. The Accounting Review, 86(5), 1605-1630. https://doi.org/10.2308/accr-10095

Falato, A., Li, D., \& Milbourn, T. (2015). Which skills matter in the market for CEOs? Evidence from pay for CEO credentials. Management Science, 61(12), 2845-2869. https://doi.org/10.1287/mnsc.2014.2024

Fan, Y., Barua, A., Cready, W., \& Thomas, W. (2010). Managing earnings using classification shifting: Evidence from quarterly special items. The Accounting Review, 85(4), 1303-1323. https://doi.org/10.2308/accr.2010.85.4.1303

Francis, B. B., Ren, N., Sun, X., \& Qiang, W. (2016). Do better managers get better loan contracts? (Working paper). https://doi.org/10.2139/ssrn.2793943

Francis, B., Sun, X., \& Wu, Q. (2015). Managerial ability and tax avoidance. Working paper Rensselaer Polytechnic Institute.

Francis, J., Huang, A. H., Rajgopal, S., \& Zang, A. Y. (2008). CEO reputation and earnings quality. Contemporary Accounting Research, 25(1), 109-147. https://doi.org/10.1506/car.25.1.4

García-Meca, E., \& García-Sánchez, I. M. (2017). Does managerial ability influence the quality of financial reporting?. European Management Journal. In Press. https://doi.org/10.1016/j.emj.2017.07.010

Ge, W., Matsumoto, D., \& Zhang, J. (2011). Do CFOs have style? An empirical investigation of the effect of individual CFOs on accounting practices. Contemporary Accounting Research, 28(4), 1141-1179. https://doi.org/10.1111/j.19113846.2011.01097.x

Graham, J., Harvey, C., \& Rajgopal, S. (2005). The economic implications of corporate financial reporting. Journal of Accounting and Economics, 40, 3-73. https://doi.org/10.1016/j.jacceco.2005.01.002

Graham, R. J., Harvey, C. R., \& Puri, M. (2013). Managerial attitudes and corporate actions. Journal of Financial Economics, 109(1), 103-121. https://doi.org/10.1016/j.jfineco.2013.01.010

Gujarati, D. (2014). Econometrics by example. Palgrave Macmillan.

https://doi.org/10.1007/978-1-137-37502-5.

Gunny, K. (2010). The relation between earnings management using real activities manipulation and future performance: Evidence from meeting earnings benchmarks. Contemporary Accounting Research, 27(3), 855-888. https://doi.org/10.1111/j.19113846.2010.01029.x

Gunny, K. A. (2005). What are the consequences of real earnings management?. Working Paper, University of Colorado.

Hambrick, D. (2007). Upper echelons theory: An update. Academy of Management Review, 32(2), 334-343. https://doi.org/10.5465/amr.2007.24345254

Hayes, R. M., \& Schaefer, S. (1999). How much are differences in managerial ability worth?. Journal of Accounting and Economics, 27(2), 125-148. https://doi.org/10.1016/S0165-4101(99)00007-5

Hribar, P., Jenkins, N., \& Johnson, W. (2006). Stock repurchase as an earnings management device. Journal of Accounting and Economics, 41, 3-27. https://doi.org/10.1016/j.jacceco.2005.10.002

Huang, X., \& Sun, L. (2017). Managerial ability and real earnings management. Advances in Accounting, 39, 91-104. https://doi.org/10.1016/j.adiac.2017.08.003 
Jackson, S., \& Wilcox, W. (2000). Do managers grant sales price reduction to avoid losses and declines in earnings and sales?. Quarterly Journal of Business and Economics, 39, 3-20.

Koester, A., Shevlin, T., \& Wangerin, D. (2016). The role of managerial ability incorporate tax avoidance. Management Science, 63 (10), 3285 - 3310. https://doi.org/10.1287/mnsc.2016.2510

Kothari, S. P., Leone, A., \& Wasley, C. (2005). Performance matched discretionary accrual measures. Journal of Accounting and Economics, 39, 163-197. https://doi.org/10.1016/j.jacceco.2004.11.002

Kothari, S. P., Mizik, N., \& Roychowdhury, S. (2016). Managing for the moment: The role of earnings management via real activities versus accruals in SEO valuation. The Accounting Review, 91(2), 559-586. https://doi.org/10.2308/accr-51153

Krishnan, G. V., \& Wang, C. (2015). The relation between managerial ability and audit fees and going concern opinions. Auditing: A Journal of Practice \& Theory, 34(3), 139-160. https://doi.org/10.2308/ajpt-50985

Laguna, M \& ,.Marklund, J .(2013) .Business process modeling, simulation and design . CRC Press. https://doi.org/10.1201/b14763

Malmendier, U., \& Nagel, S. (2011). Depression babies: do macroeconomic experiences affect risk taking?. The Quarterly Journal of Economics, 126(1), 373-416. https://doi.org/10.1093/qje/qjq004

McGuire, S., Omer, T., \& Sharp, N. (2012). The impact of religion on financial reporting irregularities. The Accounting Review, 87(2), 645-673. https://doi.org/10.2308/accr$\underline{10206}$

McVay, S. (2006). Earnings management using classification shifting: An examination of core earnings and special items. The Accounting Review, 81, 501-531. https://doi.org/10.2308/accr.2006.81.3.501

Milbourn, T. T. (2003). CEO reputation and stock-based compensation. Journal of Financial Economics, 68(2), 233-262. https://doi.org/10.1016/S0304405X(03)00066-7

Petrou, A. P., \& Procopiou, A. (2016). CEO shareholdings and earnings manipulation: a behavioral explanation. European Management Review, 13(2), 137-148. https://doi.org/10.1111/emre.12073

Roychowdhury, S. (2006). Earnings management through real activities manipulation. Journal of Accounting and Economics, 42, 335-370. https://doi.org/10.1016/j.jacceco.2006.01.002

Siao, W. S., \& Chou, T. K. (2013). Does Managerial Ability Improve Value of Cash Holdings. Working paper.

Zang, A. (2012). Evidence on the trade-off between real activities manipulation and accrual-based earnings management. The Accounting Review, 87(2), 675-703. https://doi.org/10.2308/accr-10196 